University of Arkansas, Fayetteville

ScholarWorks@UARK

Graduate Theses and Dissertations

8-2014

\title{
Field-Obtained Soil Water Characteristic Curves and Hydraulic Conductivity Functions
}

Elvis Ishimwe

University of Arkansas, Fayetteville

Follow this and additional works at: https://scholarworks.uark.edu/etd

Part of the Civil Engineering Commons, Geophysics and Seismology Commons, and the Geotechnical Engineering Commons

Citation

Ishimwe, E. (2014). Field-Obtained Soil Water Characteristic Curves and Hydraulic Conductivity Functions. Graduate Theses and Dissertations Retrieved from https://scholarworks.uark.edu/etd/2158

This Thesis is brought to you for free and open access by ScholarWorks@UARK. It has been accepted for inclusion in Graduate Theses and Dissertations by an authorized administrator of ScholarWorks@UARK. For more information, please contact scholar@uark.edu. 
Field-Obtained Soil Water Characteristic Curves and Hydraulic Conductivity Functions 
Field-Obtained Soil Water Characteristic Curves and Hydraulic Conductivity Functions

A thesis submitted in partialfulfillment of the requirements for the degree of

Master of Science in Civil Engineering

by

\author{
Elvis Ishimwe \\ University of Arkansas \\ Bachelor of Science in Civil Engineering, 2013
}

August 2014

University of Arkansas

This thesis is approved for recommendation to the Graduate Council.

Dr. Richard A. Coffman

Thesis Director

Dr. Norman D. Dennis

Dr. Michelle Bernhardt

Committee Member

Committee Member 


\begin{abstract}
A compacted clay liner (test pad) was constructed and instrumented with volumetric water content and soil matric potential sensors to determine soil water characteristic curves (SWCC) and hydraulic conductivity (k) functions. Specifically, the compacted clay liner was subjected to an infiltration cycle during a sealed double ring infiltrometer (SDRI) test followed by a drying cycle. After the drying cycle, Shelby tube samples were collected from the compacted clay liner and flexible wall permeability (FWP) tests were conducted on sub-samples to determine the saturated hydraulic conductivity. Moreover, two computer programs (RETC and UNSAT-H) were utilized to model the SWCCs and k-functions of the soil based on obtained measurements including the volumetric water content $\left(\theta_{\mathrm{v}}\right)$, the soil matric potential $(\psi)$, and the saturated hudraulic conductivity $\left(k_{s}\right)$.

Results obtained from the RETC program $\left(\theta_{s}, \theta_{r}, \alpha, n\right.$ and $\left.k_{s}\right)$ were ingested into UNSATH program to calculate the movement of water (rate and location) through the compacted clay liner. Although a linear wetting front (location of water infiltration as a function of time) is typically utilized for SDRI calculations, the use of a hyperbolic wetting front is recommended as a hyperbolic wetting front was modeled from the testing results. The suggested shape of the wetting front is associated with utilization of the desorption SWCC instead of the sorption SWCC and with relatively high values of $k_{s}$ (average value of $7.2 \mathrm{E}-7 \mathrm{~cm} / \mathrm{sec}$ ) were measured in the FWP tests while relatively low values of $k_{s}$ (average value of $1.2 \mathrm{E}-7 \mathrm{~cm} / \mathrm{sec}$ ) were measured in the SDRI test.
\end{abstract}




\section{Acknowledgments}

I would like to express the deepest appreciation to my thesis director, Dr. Richard A. Coffman for giving me the opportunity to conduct this research and guiding me along the way. Without his guidance, mentorship and persistent help this thesis would not have been possible. I would also like to thank my committee members, Dr. Norman D. Dennis and Dr. Michelle Bernhardt for being extraordinary committee members who showed me the road and helped to get me started on the path to this degree. I would also like to thank Cyrus Garner for assisting me to collect and reduce data for the research presented in this document. Also, a special thanks goes out to the students: Sarah Bey, Cyrus Garner, Morgan Race, Yi Zhao, Michael Deschenes, Sean Salazar and Nabeel Mahmood for helping me to construct the test pad. 


\section{Table of Contents}

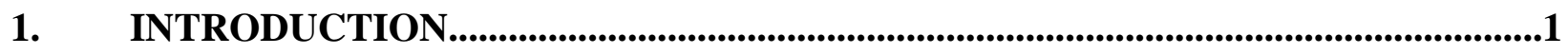

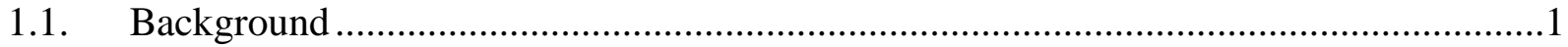

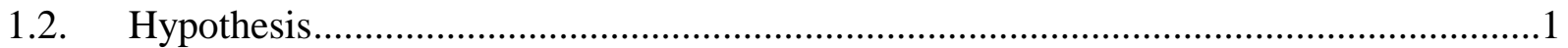

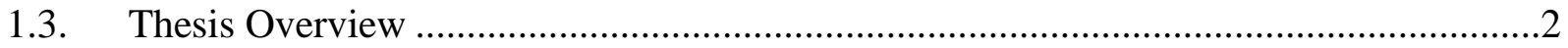

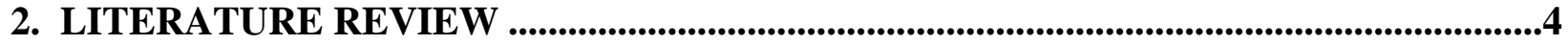

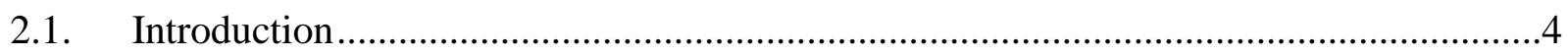

2.2. Soil Water Characteristic Curve Function (SWCC function) ...................................4

2.3. Hydraulic Conductivity Function (k-function) .................................................6

2.4. In-situ Instrumentation Utilized to Measure Soil Matric Potential and Volumetric

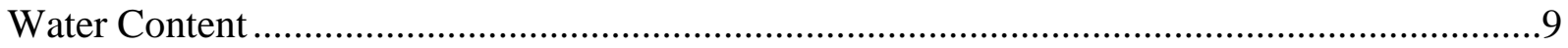

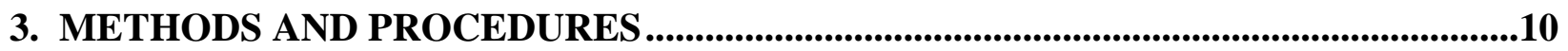

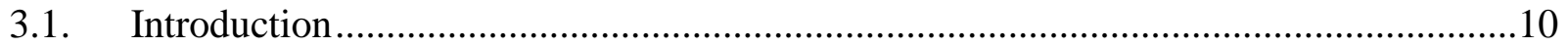

3.2. Compacted Clay Liner Construction and Testing .................................................10

3.3. Compacted Clay Liner Modeling ....................................................................13

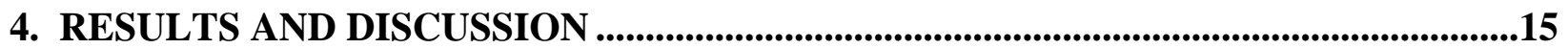

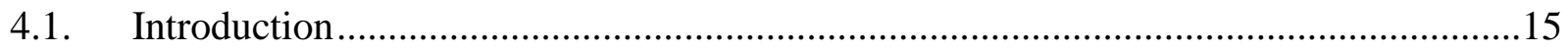

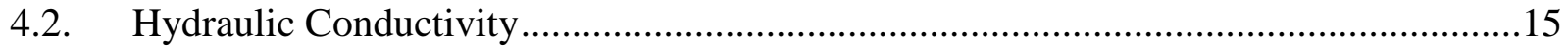

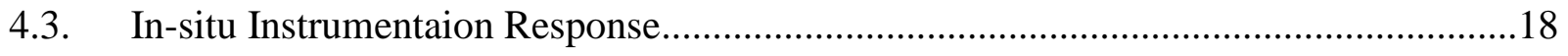

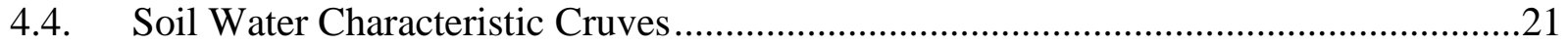

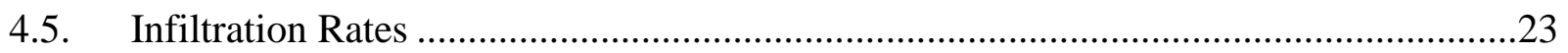

4.6. Field-obtained SWCC Testing Procedure and Results .........................................26

5. CONCLUSIONS AND RECOMMENDATIONS ........................................................29 


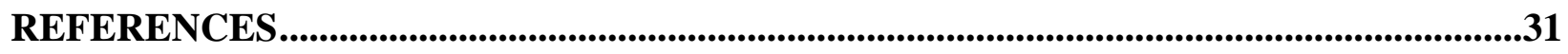

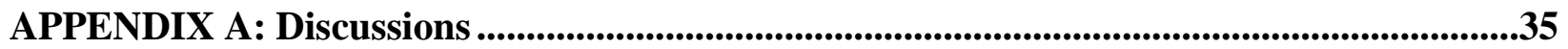

Discussion on Zone of Acceptance and Nuclear Gauge Density Testing Results..............35

Discussion on In-situ Hydraulic Conductivity Results Obtained Using SDRI test............38

Discussion on Laboratory Hydraulic Conductivity Results Obtained Using FWP Tests.41

Discussion on Results Obtained Using In-situ Instrumentation....................................41

Discussion on Measured Field SWCC and k-functions...........................................43 


\section{List of Figures}

Figure 1: Schematic of instrumented compacted clay liner (a) cross-section, and (b) plan

view

Figure 2: Results obtained from SDRI testing 16

Figure 3: Results obtained from FWP testing. 16

Figure 4: In-situ density and water content values from the compacted clay liner and the zone of acceptance from Coffman and Maldonado (2011) and Nanak (2012).

Figure 5: Time-dependent response of the TDR probes located within the compacted clay liner

Figure 6: Time-dependent response of the WMPS probes located within the compacted clay liner.

Figure 7: Time-dependent response of the tensiometers probes located within the compacted clay liner 20

Figure 8: Soil water characteristic curves as obtained from data collected from TDR and WMPS during drying cycle (desorption)

Figure 9: Soil water characteristic curves as modeled from field-obtained data in RETC software program

Figure 10: Modeled k-function compared to the k-values obtained from SDRI and FWP tests

Figure 11: Infiltration rate as measured using field equipment and modeled using the UNSAT-H software program 25

Figure 12: Photograph of dessication cracking within the compacted clay liner following the drying cycle (picture taken by the author) 27 
Figure 13: Nuclear density gauge testing locations.....

Figure 14: Summary of Infiltration and cumulative time obtained during SDRI testing 38 Figure 15: Summary of wetting front and cumulative time obtained during SDRI testing

Figure 16: Summary of hydraulic gradient and cumulative time obtained during SDRI

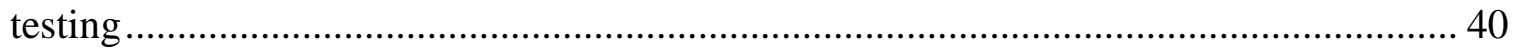

Figure 17: Field obtained SWCCs using TDR and WMPS data ................................. 44 


\section{List of Tables}

Table 1: Summary of measured and predicted hydraulic conductivity values ............... 28

Table 2: Results of nuclear density gauge tests from the top of each layer of the test pad

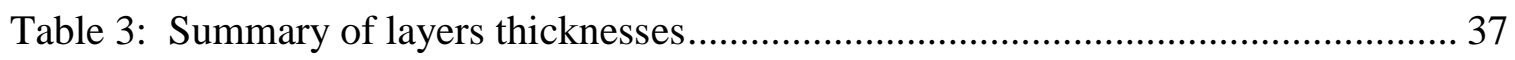

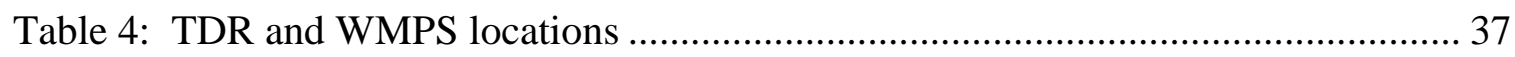

Table 5: Data recorded during SDRI testing ..................................................... 45

Table 6: Summary of results obtained from SDRI testing ..................................... 46

Table 7: Summary of in-situ hydraulic conductivity results obtained from SDRI testing.47 


\section{INTRODUCTION}

\subsection{Background}

Soil water characteristic curves (SWCCs) are useful in determining the unsaturated properties of soils such as the hydraulic conductivity, shear strength, and coefficients of diffusion and adsorption (Fredlund and Rahardjo 1993, Fredlund and Xing 1994, and Fredlund et al. 1996). Historically, SWCCs have been obtained in the laboratory using laboratory equipment (Klute et al. 1986, Wang and Benson 2004, Mijares and Khire 2010, ASTM D 6836; Wayllace and Lu 2012), however, SWCCs have also been obtained in the laboratory using field testing equipment (Watson et al. 1975; Beese and van der Ploeg 1976; Tzimas 1979; Li et al. 2004, Ogorzalek et al. 2007). The unsaturated soil properties that were obtained in the laboratory, using field-testing equipment, for a laboratory-scale compacted clay liner ( $3 \mathrm{~m}$ wide by $3 \mathrm{~m}$ long by $0.6 \mathrm{~m}$ thick) are presented and discussed. Specifically, the compacted clay liner and the instrumentation utilized to collect the data are examined and the results obtained from laboratory and field hydraulic conductivity testing on the compacted clay liner soil are compared with results that were predicted by modeling the behavior of the compacted clay liner using the UNSAT-H program.

\subsection{Hypothesis}

The hypothesis for the proposed research is that unsaturated and saturated soil parameters including values of: hydraulic conductivity, volumetric water content, soil temperature and soil matric potential can be effectively measured or calculated using field-scale equipment. The hypothesis was evaluated by completing several tasks; each of the tasks will 1) 
fulfill one objective and 2) be comprised of several activities. The objectives for this research are itemized below.

- To conduct conventional geotechnical tests in the laboratory to thoroughly characterize the soil that will be used in this research program.

- To develop a full-scale testing procedure to determine the SWCC and k-function.

- To assess the mechanisms of drying and wetting, with a particular emphasis on the interpretation of the full-scale field testing results and on the comparison of the results obtained from the full-scale field testing with the results obtained from conventional geotechnical laboratory tests.

- To modify or develop models and relationships that are necessary for subsequent use of fullscale test results for geotechnical applications.

- To transfer the findings from this research into recommendations and approaches that are suitable for use while characterizing unsaturated soil within the global practice of geotechnical engineering.

\subsection{Thesis Overview}

The thesis presented herein is divided into five chapters. The introduction of the reseach conducted, the hypothesis and this overview are included in Chapter 1. Further details about previous research on SWCCs and k-functions (as obtained from laboratory testing, empirical correlations, and theoretical models), and a literature review of in-situ instrumentation employed in this research are discussed in Chapter 2. The methods and procedures that were utilized to complete this research, including the compacted claly liner (test pad) construction and SDRI testing and compacted clay liner modeling are discussed in Chapter 3. Contained in Chapter 4 are 
the results and discussion of hydraulic conductivity results, in-situ instrumentation response, the results of soil water characteristic curves, infiltration and field -obtained SWCC testing procedure and results. Chapter 5 contains conclusions drawn based on the results obtained from the reseach presented in this document and recommendations for future testing. References are also provided for completeness. Further detailed discussion on the soil placement, field and laboratory testing results, and measured SWCC and k-functions are also presented in Appendix A. 


\section{LITERATURE REVIEW}

\subsection{Introduction}

Numerous researchers have investigated unsaturated soils. Although the topic of unsaturated soils is relatively new (intensively investigated for the past 25 years), several textbooks have been written on the subject (Fredlund and Rajahdo 1993, Lu and Likos 2004a) with SWCC and k-functions also being discussed in details in journal articles (eg., Ogorzalek et al. 2008, Wayllace and Lu 2012, Lu and Kaya 2013, Lu et al. 2014). For instance, Fredlund and Rajahdo (1993) developed a rational engineering approach to describe the behavior of unsaturated soil in terms of stress state while Likos and Lu (2012) discussed the three fundamental constitutive relations (soil water retention curve, hydraulic conductivity function and suction stress characteristic curve) that are used to define fluid flow, strength and deformation behavior of unsaturated soil (Lu and Godt 2014).

\subsection{Soil Water Characteristic Curve Function (SWCC function)}

The soil water characteristic curve (SWCC) has been utilized as the primary constitutive relationship for interpreting the engineering behavior of unsaturated soils. In recent years, the SWCC has become an important tool for predicting the mechanical and hydraulic properties of unsaturated soils (Fernando 2005). Unsaturated soil properties such as the hydraulic conductivity, shear strength, and coefficients of diffusion and adsorption can all be predicted from SWCCs (Fredlund and Rahardjo 1993, Fredlund and Xing 1994, and Fredlund et al. 1996). The SWCC is typically S- or J- shaped and is hysteretic. The shape of the SWCC is generally influenced by soil type, mineralogy, density, initial water content, soil structure, texture, stress 
history, method of compaction and net confining stress (Tinjum et al. 1997, Vanapalli et al. 1999, Lu and Likos 2004, Thu et al. 2007).

Several laboratory techniques exist for measuring the SWCC (Klute et al. 1986, Wang and Benson 2004, Mijares and Khire 2010, ASTM D 6836; Wayllace and Lu 2012). Field-scale measurement of SWCCs is expensive; consequently, most of researchers determined SWCCs in the laboratory on the small soil samples. However, few literature of field SWCC were also published (Watson et al. 1975; Beese and van der Ploeg 1976; Tzimas 1979; Li et al. 2004, Ogorzalek et al. 2007). For instance, Waston et al, 1975 measured the field SWCC using a triangular pyramid frame housing instrumentation (described by Reginato and Jackson 1971a) to determine the water content and tensiometers to measure the soil water pressure. Li et al. 2004 also measured the field SWCCs at the crest and berm of a large cut slope in Hong Kong using TDR moisture probes and vibrating wire tensiometers to measure soil water content and soil matric suction, respectively while Ogozalek et al 2007 used TDR probes and thermal dissipation sensor to measure soil suction to define SWCC for a capillary barrier cover in Polston, Montana.

Previous researchers have developed many theoretical models to successful represent the experimental results of the SWCC into mathematical models (Burdine 1953, Brooks and Corey 1964, Mualem 1976, van Genuchten 1980, McKee and Bumb 1987, Kosugi 1994, Fredlund and Xing 1994, and Frydman and Baker 2009). A comprehensive description of these models is provided in Sillers et al. (2001). Of these models, the van Genuchten (1980) model is commonly used to represent SWCC data. The van Genuchten (1980) model provides a continuous SWCC using three fitting parameters ( $\mathrm{a}, \mathrm{n}$ and $\mathrm{m}$ ), and the model better matches experimental data than Brooks and Corey 1964 model. The model is determined using the following equation: 
$S=\frac{1}{\left[1+(a \psi)^{n}\right]^{m}}$

(Sillers et al. 2001)

Equation 1

In Equation 1, a is fitting parameter related to inverse of air entry; $n$ is related to the pore size distribution of the soil; $m$ is a parameter related to the asymmetry for the model; $\psi$ is the soil matric suction; $S$ is the normalized water content of the soil given by $S=\left(\theta-\theta_{r}\right)\left(\theta_{s}-\theta_{r}\right) ; \theta$ is volumetric water content; $\theta_{r}$ is residual water content; and $\theta_{s}$ is the saturated water content.

As discussed in Topp and Miller (1966) and Kool and Parker (1987), a hysteresis between the wetting and drying curves is observed in the SWCC. However, hyperbolic or polynomial functions have been fitted experimental data to produce a SWCC. Several computer programs such as LEACH-M, RETC, UNSAT-H, HYDRUS, Vadose/W, and SEEP/W were also developed and utilized to represent the experimental results into existing parametric models and to simulate the water movement through the soil. Furthermore, the aforementioned theoretical models are employed in these numerical codes to successful define SWCC. For instance, the parametric models of Brooks-Corey (1964) and van Genuchten (1980) are utilized in RETC program to represent the SWCC, and the theoretical pore-size distribution models of Mualem (1976) and Burdine (1953) to predict the unsaturated k-function from the measured SWCC data.

\subsection{Hydraulic Conductivity Function (k-function)}

The k-function represents the proportionality between the hydraulic gradient and water flow rate, and thus is only relevant for conditions in which the water phase in the soil is continuous. According to Lu and Godt (2014), the hydraulic conductivity of the soil is no longer a constant and typically is portrayed as function of either the degree of saturation or suction of the soil. K-functions, which define as relationship between hydraulic conductivity $(\mathrm{k})$ and water content or suction, have been determined in the laboratory using rigid- and flexible-wall permeameters with flow being controlled by surface infiltration/gravity drainage and by pumps, 
respectively (Benson and Gribb 1997, Meerdink et al. 1996, Lu and Likos 2005). Based on the original work by Olson and Daniel (1981), a transient period (changes in volumetric water content and suction) was followed by steady state flow conditions (no changes in volumetric water content and suction). Transient measurements have been used to measure the k-function; however, there was a significant amount of scatter in the data. As shown by Moore (1939), steady-state flow data reduce the scatter in the data but require much longer testing periods.

The hydraulic conductivity of a compacted clay liner is typically determined using laboratory and in-situ test methods. However, as described in Day and Daniel (1985), a significant difference between hydraulic conductivity values obtained in the laboratory and in the field has been observed by many researchers. In order to compensate that difference laboratory tests are conducted and clay liner test pads are constructed to correlate the laboratory results to the actual field hydraulic conductivity. Additionally, many regulatory agencies in United States require in-situ tests in addition to laboratory tests to confirm the measured hydraulic conductivity and the competency of clay liners (Trautwein and Boutwell 1994).

Many different in-situ and laboratory tests including flexible wall permeameter (ASTM D 5084), rigid wall permeameter (ASTM D5856), air-entry permeameter, open double ring infiltrometer (ASTM D3385), sealed double ring infiltrometer (ASTM D5093) and two-stage borehole tests (ASTM D6391) have proposed and used to determine the hydraulic conductivity of the soil. Of these, Flexible Wall Permeability (FWP) and Sealed Double Ring Inflitrometer (SDRI) tests were used in the analysis of this paper. Specifically, in the laboratory, the FWP test was developed to minimize the sidewall leakage that were previously observed in the rigid wall permeameters, to monitor the back pressure in the testing sample, and also to control both horizontal and vertical effective stresses during testing. The FWP is conducted in accordance 
with ASTM D5084 and Equation 2 is used to determine the hydraulic conductivity (k)of the soil, and then $\mathrm{k}$ is corrected to the standard temperature of 20 degrees Celsius (Equation 3 and 4).

$$
\begin{array}{lll}
k=\frac{a_{\text {in }} a_{\text {out }} * L}{\left(a_{\text {in }}+a_{\text {out }}\right) * A * \Delta t} \ln \left(\frac{\Delta h_{1}}{\Delta h_{2}}\right) & (\text { ASTM D5084, 2012) } & \text { Equation 2 } \\
k_{20}=R_{T} * k & (\text { ASTM D5084, 2012) } & \text { Equation 3 } \\
R_{T}=2.2902^{*}\left(0.9842^{T}\right) / T^{0.1702} & (\text { ASTM D5084, 2012) } & \text { Equation 4 }
\end{array}
$$

In the Equation 2 through $4, a_{i n}$ is the cross-sectional area of reservoir containing influent/inflow liquid; $a_{\text {out }}$ is the cross-sectional area of the reservoir containing the effluent/outflow liquid; $L$ is the length of soil sample; $A$ is the cross-sectional area of soil sample; $\Delta h_{1}$ is the head loss across the permeameter at t $t_{1}$ of water; $\Delta h_{2}$ is the head loss across the permeameter at $t_{2}$ of water; $k_{20}$ is the hydraulic conductivity corrected to $20^{\circ} \mathrm{C}\left(68^{\circ} \mathrm{F}\right) ; R_{T}$ is the ratio of viscosity of water at test temperature to viscosity of water at $20^{\circ} \mathrm{C}$; T is an average test temperature during the permeation trial $\left(\left(T_{1}+T_{2}\right) / 2 ; T_{1}\right.$ is the test temperature at start of permeation trial; and $T_{2}$ is the test temperature at end of permeation trial.

The SDRI test, which was first developed by Daniel and Trautwein (1986), is an in-situ test that is commonly used to accurately measure the hydraulic conductivity of the soil. Unlike laboratory hydraulic conductivity tests, SDRI testing was developed to test larger and more representative volumes of material, allowing the permeating liquid to flow through secondary features (Daniel 1989). The installation and operation of the SDRI test were documented in Trautwein Soil Testing Equipment Co. (1987), Trautwein and Boutwell (1994), and ASTM D5093 (2012). The values of hydraulic conductivity from SDRI test are general obtained using the equation 5, 6 and 7 that are based on Darcy's law. However, the calculation of hydraulic gradient (equation 7) was determined to be complicated because the soil to be tested is initially unsaturated (Trautwein and Boutwell, 1994). Therefore, three methods (Apparent, Suction Head and Wetting Front method) were proposed by Trautwein and Boutwell (1994) to estimate the hydraulic gradient during SDRI testing. Details on these methods can be found in Trautwein and Boutwell (1994) and Nanak (2012). 
$I=\frac{Q}{t A}$

$k=\frac{I}{i} F$

$i=\frac{H+Z_{w}+H_{S}}{Z_{w}}$
(Daniel and Trautwein, 1986)

(Daniel and Trautwein, 1986)

(Trautwein and Boutwell, 1994)
Equation 5

Equation 6

Equation 7

In Equations 5 through 7, $I$ is the infiltration rate; $Q$ is the volume of flow $\left(Q=W_{1}-W_{2}\right)$; W is the initial weight of bag; $W_{2}$ is final weight of bag; $t$ is time of flow $\left(t=t_{2}-t_{1}\right) ; t_{1}$ is the time when shut-off valve on bag was opened; $t_{2}$ is the time when the shut-off valve on bag was closed; $A$ is an area of inner ring; $k$ is hydraulic conductivity; $i$ is hydraulic gradient; $F$ is correction factor to account for the lateral spreading of water; $H$ is head of water above the soil surface; $H_{s}$ is suction head at location of the wetting front; and $Z_{w}$ is the depth of wetting front below the soil surface.

\subsection{In-situ Instrumentation Utilized to Measure Soil Matric Potential and Volumetric Water Content}

Like the laboratory techniques mentioned previously, several techniques have been utilized to determine the soil matric suction $(\psi)$ and volumetric water content $\left(\theta_{\mathrm{v}}\right)$ of soil in the field (in-situ), and these parameters can be used to determine SWCC and k-functions. For instance, the time domain reflectrometry (TDR) technique have been used to determine volumetric water content, the use of TDR sensors were presented in the literature (Topp et al. 1980; Menziani et. al 1996; Nemmers 1998; Evett 2003; Campbell Scientific 2013; Garner and Coffman 2014), water matric potential sensors (WMPS) technique have been employed to capture the soil matric potential and temperature (Reece 1996 and Phene et al. 1996, Campbell

Scientific 2013), and also tensiometers are commonly used to measure soil matric potential in the field (Trautwein and Boutwell 1994, Ridley et al. 1998, and Take and Bolton 2003). 


\section{METHODS AND PROCEDURES}

\subsection{Introduction}

The investigation that was performed, and is discussed herein, consisted of 1) constructing and instrumenting a compacted clay liner, 2) performing a SDRI test, 3) allowing the soil to dry during a drying cycle, and 4) performing FWP tests on soil sub-samples that were obtained from Shelby tube samples that were collected from the compacted clay liner. In addition to methods and procedures utilized to perform the laboratory testing, modeling was also performed using the RETC and UNSAT-H software programs. Specifically, the laboratory obtained data were utilized within the RETC and UNSAT-H programs to determine the infiltration rate through the compacted clay liner.

\subsection{Compacted Clay Liner Construction and Testing}

A $3 \mathrm{~m}$ wide by $3 \mathrm{~m}$ long by $0.6 \mathrm{~m}$ thick compacted clay liner was constructed by compacting four-lifts of soil. Each lift was placed as a $0.2 \mathrm{~m}$ thick loose lift and compacted to a $0.15 \mathrm{~m}$ thick compacted lift within the wooden box described by Maldonado and Coffman (2012). The thickness of the laboratory-scale compacted clay liner resembled a full-scale compacted clay liner. However, due to size limitations in the laboratory, the laboratory-scale compacted clay liner was compacted using a ramming compactor instead of a kneading compactor. The soil, classified as a low plasticity clay (CL), was placed within the zone of acceptance (Figure 4) and following the methods described in in Maldonado and Coffman (2012) and Nanak (2012). Detailed discussions are presented in Appendix A.

During compaction, instrumentation was installed into the compacted clay liner. Two Campbell Scientific CS-610 time domain reflectometry (TDR) probes and two Campbell 
Scientific CS-229 water matric potential sensors were installed $0.05 \mathrm{~m}$ below the top of each lift by excavating soil from the surface (for a total of 4 TDR probes and 4 WMPS) and installed following the methods described in Garner and Coffman (2012). Following compaction, two sets of Irrometer Model S, E-gauge, tensiometers were installed at depths of $0.13 \mathrm{~m}, 0.27 \mathrm{~m}$, and $0.58 \mathrm{~m}$ (for a total of 6 tensiometers) and a Trautwein Soil Testing Equipment Co. $2.4 \mathrm{~m}$ outer ring and $0.46 \mathrm{~m}$ inner ring sealed double ring infiltrometer (SDRI) were also installed. The infiltration was measured by connecting a flexible bag filled with a known amount of water to the inner ring and a certain interval of time, the bag was removed from the inner ring and weighed. The weight loss was equal to the amount of water infiltrated through the soil. The sealed inner ring was utilized to eliminate the evaporation loss, and outer ring was used to promote one dimensional vertical flow below the inner ring.

The sensors were installed below the inner ring to accurately capture the change of the saturated/unsaturated soil properties during SDRI testing and drying cycle. The locations of the sensors and SDRI equipment are shown in Figure 1. Specifically, Campbell Scientific CS-610 30 cm-long time domain reflectrometry probes and Campbell Scientific CS-229 heat dissipation water matric potential sensors along with data acquisition system consisted of two Campbell Scientific CR-10X, two Campbell Scientific 16 channel AM-416 relay multiplexers, a Campbell Scientific eight channel SDMX-50 coaxial multiplexer and a Campbell Scientific TDR-100 time domain reflectrometer were employed to automatically monitor the volumetric water content and soil matric potential (soil suction) continuously (hourly readings).

A sealed double ring infiltrometer test was then conducted following the procedures outlined in Trautwein Soil Testing Equipment Co. (1987), Trautwein and Boutwell (1994), and ASTM D5093 (2014). Upon completion of the 69-day SDRI test the water that was ponded 
within both rings was drained and the compacted clay liner was allowed to undergo a drying cycle. The instrumentation within the compacted clay liner continued to collect continuous data during the drying cycle. The soil was allowed to dry for 86 days under an average temperature of $20^{\circ} \mathrm{C}$, with no direct sunlight, and no direct wind; desiccation cracks were observed to develop at the soil surface. Two Shelby tube samples were collected from the compacted clay liner at the locations shown in Figure 1b. Four FWP tests were conducted, in accordance with ASTM D5083 (2014), on sub-samples that were removed from one of the Shelby tubes. The other Shelby tube was retained for future laboratory-based determination of the SWCCs using the transient release and imbibition method (TRIM).

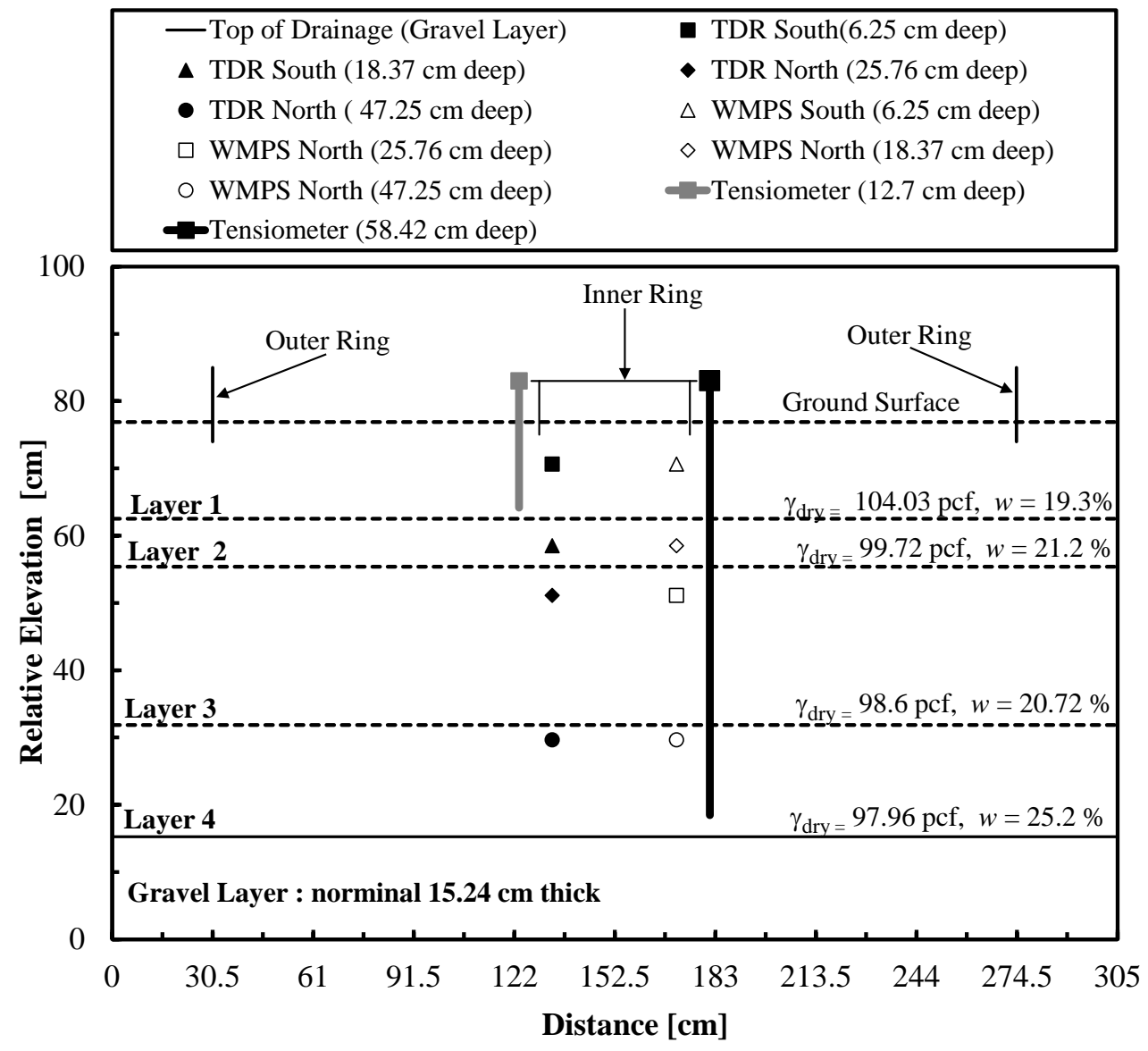

(a) 


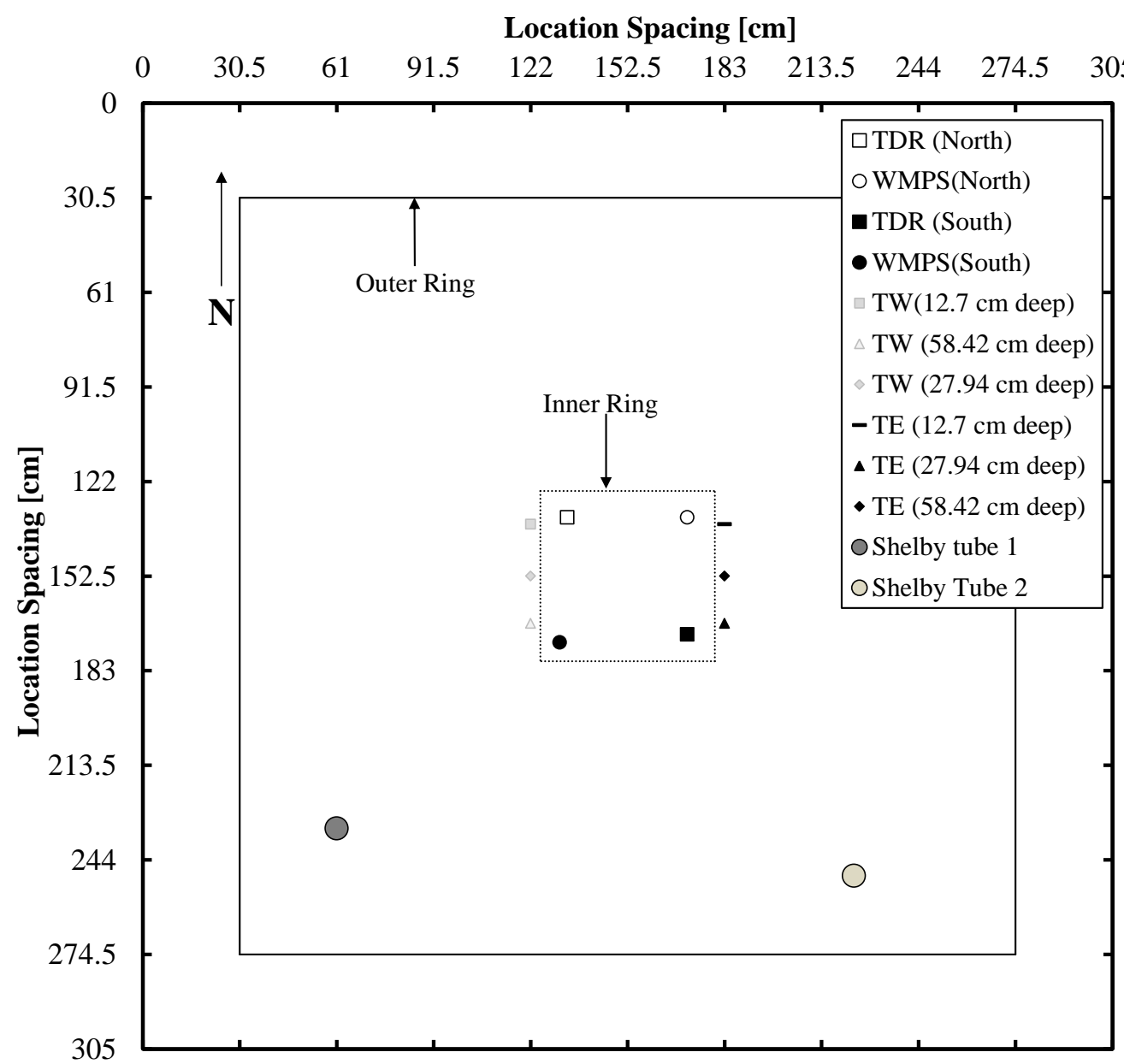

(b)

Figure 1. Schematic of the instrumented compacted clay liner (a) cross-section, and (b) plan view.

\subsection{Compacted Clay Liner Modeling}

The amount of time required for the wetting front to reach each of the sensors (TDR, SWMP, and tensiometers) was deduced from the data obtained from the in-situ instrumentation. Furthermore, the data obtained from the in-situ instrumentation (volumetric water content and soil suction) were utilized to develop SWCCs corresponding to the various depths at which the sensors were located. The measured SWCC data were then fit using the RETC program and the measured hydraulic conductivity values for the respective layers (as obtained from the FWP tests conducted on the potentially desiccated soil samples that were obtained from the Shelby tube 
samples collected following the drying cycle) were also ingested into the RETC program. Specifically, the van Genuchten (1980) parametric model and the Mualem (1976) theoretical pore-size distribution model were utilized in the RETC program to determine the van Genuchten (1980) SWCC fitting parameters and the hydraulic conductivity function (k-function). The SWCC parameters and the k-function were then combined with the physical properties of the compacted clay liner (layer thicknesses, unit weights, water contents, etc.) within the UNSAT-H program to simulate the infiltration rate of the soil. 


\section{RESULTS AND DISCUSSION}

\subsection{Introduction}

The results obtained utilizing the aforementioned testing procedure include: 1) saturated hydraulic conductivity values for in-situ soil and for sampled soil that had been subjected to a drying cycle, 2) the time-dependent response of the soil as measured using in-situ instrumentation, 3) the soil water characteristic curves and hydraulic conductivity functions, and 4) the modeled infiltration rate. All of the obtained data are presented and discussed. In addition, the modeled values of the SWCC parameters, the k-functions, and the infiltration rate are also compared with the measured values of the respective properties. Furthermore, based on the lessons learned from this study, a detailed procedure is presented for determining field-obtained soil water characteristic curves.

\subsection{Hydraulic Conductivity}

The hydraulic conductivity data that were collected in-situ immediately after compaction, using the SDRI testing technique, and after the drying cycle, using the FWP technique, are presented in Figures 2 and 3, respectively. The in-situ hydraulic conductivity values from SDRI tests were determined using Equations 5,6, and 7 presented in Chapter 2. The hydraulic gradient (i) was obtained using the three methods (Apparent Hydraulic Conductivity, Suction Head and Wetting Front Method) and tensiometers data (to monitor the progression/location of the wetting front). The laboratory hydraulic conductivity values were obtained from FWP using Equation 2, 3, and 4. The FWP testing was conducted until the outflow and inflow rate ranged between 0.75 to 1.25), and the average of the four last points (open symbols in Figure 3) was considered as the final laboratory hydraulic conductivity of the soil. 


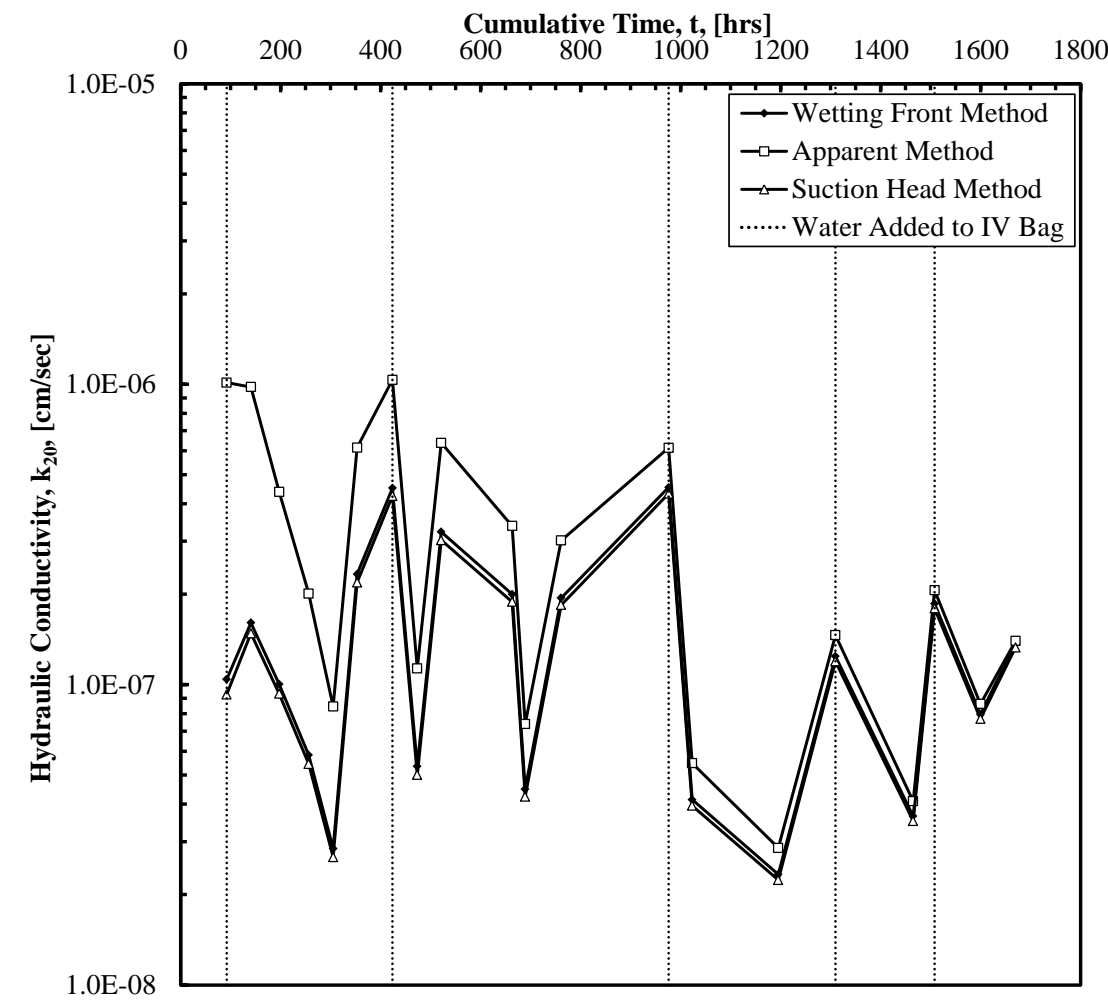

Figure 2. Results obtained from SDRI testing.

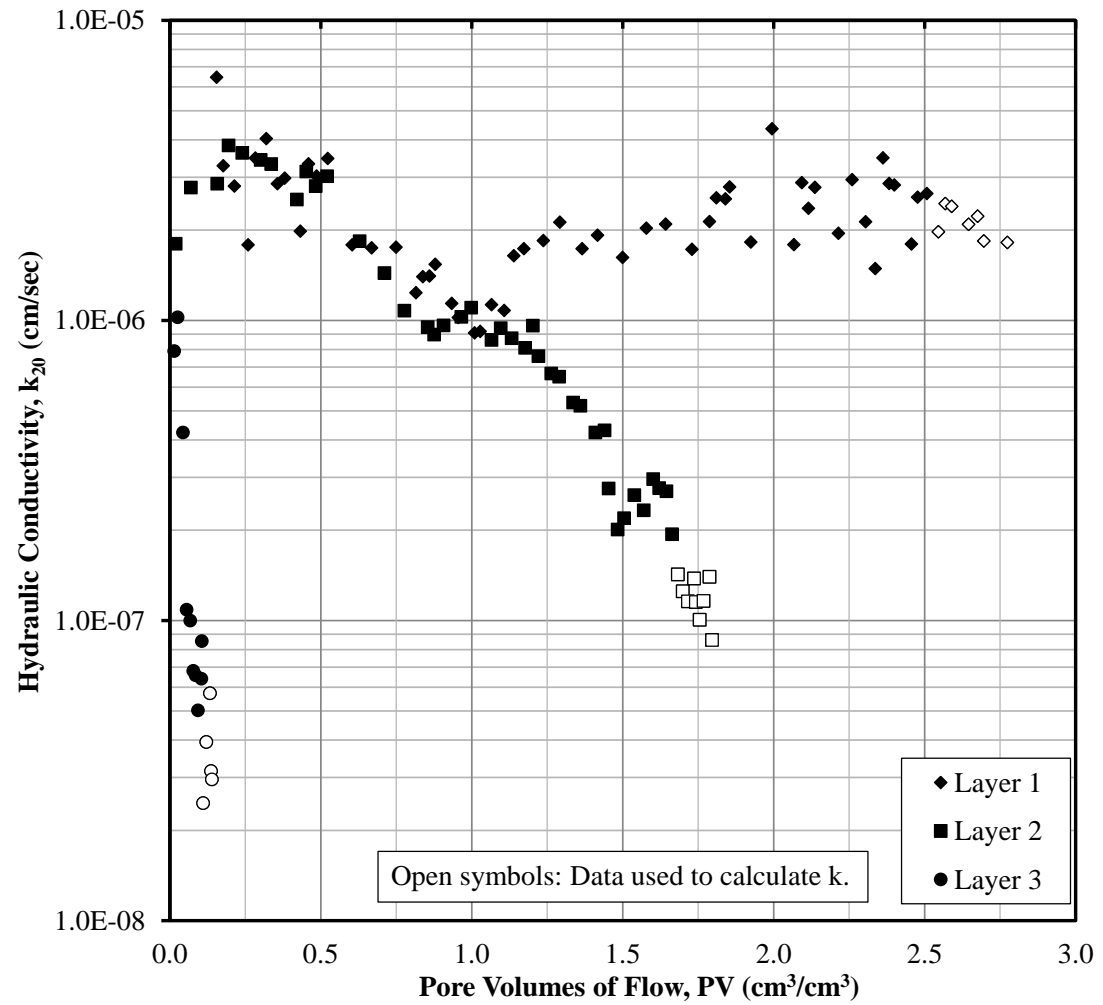

Figure 3. Results obtained from FWP testing. 
As expected, the values of the hydraulic conductivity that were obtained from the FWP tests were higher than the values of hydraulic conductivity that were obtained from the SDRI test. The reason for the difference was attributed to the following: 1) the SDRI data were obtained immediately after compaction and prior to the drying cycle, 2) the FWP data were obtained from samples that were subjected to the drying cycle (samples that were subjected to desiccation), 3) the cross-sectional areas of samples that were tested in the SDRI test and the FWP tests were of different size.

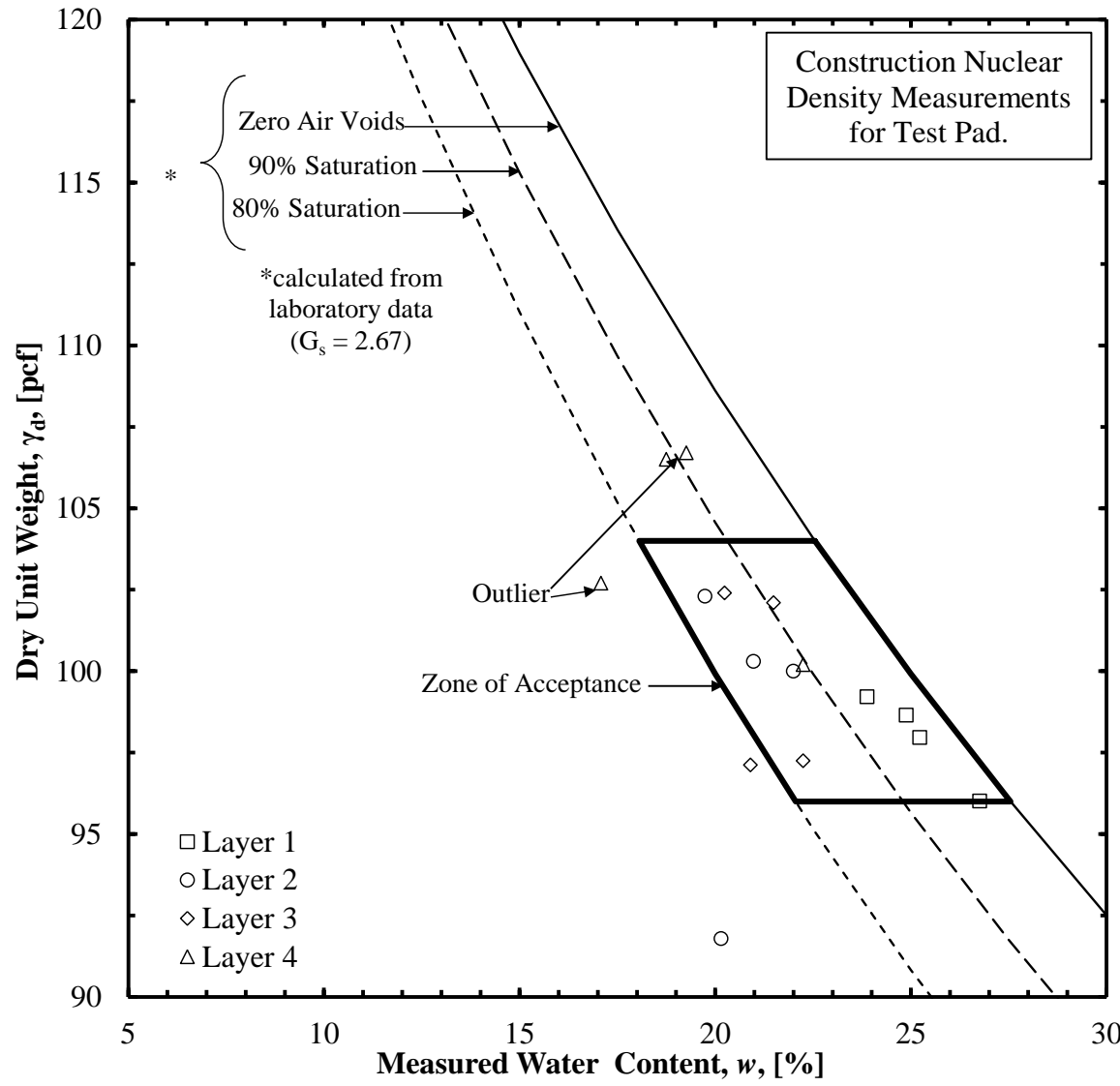

Figure 4. In-situ density and water content values from the compacted clay liner and the zone of acceptance from Coffman and Maldonado (2011) and Nanak (2012).

Because the soil was compacted to ensure that the dry density and water content were within the zone of acceptance except for a few outliers (Figure 4), the measured hydraulic 
conductivity values that were obtained from the SDRI test were very close to (albeit above) the regulatory requirement of $1.0 \mathrm{E}-7 \mathrm{~cm} / \mathrm{sec}$ (Table 1). Specifically, the hydraulic conductivity values that were obtained for Layer 3 from the SDRI test were lower than the regulatory limit when using the wetting front method or the suction method. These methods are more representative of the field conditions, than the apparent method, because the amount of suction at the wetting front is assumed to be zero or equal to the measured value of suction, respectively.

\subsection{In-situ Instrumentaion Response}

The time-dependent responses of the in-situ instrumentation corresponding to the data obtained from the TDR probes, the WMPS, and the tensiometer probes are presented in Figures 5,6 , and 7, respectively. These data were utilized for 1) identifying the amount of time required for the wetting front to reach the probes, based on data collected during the wetting cycle, and 2) developing SWCCs, based on data collected during the drying cycle. As observed in the response of all of the instrumentation, the amount of increase in the volumetric water content and soil suction, as observed during the wetting cycle, was negligible compared to the amount of decrease in these values during the drying cycle. This response was expected because the soil was compacted on the wet side of the optimum water content within the zone of acceptance that was developed to ensure low permeability of the compacted clay liner. Owing to the malfunction of the data acquisition and shortcoming of the sensors, only data collected from four TDR and four WMPS (one TDR and one WMPS within each layer) sensors were used in this study. As shown in Figure 5 and 6, both parameters decreased during the drying cycle and significant changes in volumetric water content and matric suction occurred mostly wthin the upper layer (Layer 1) because within this layer the influence of evaporation was greated than in other layers. 


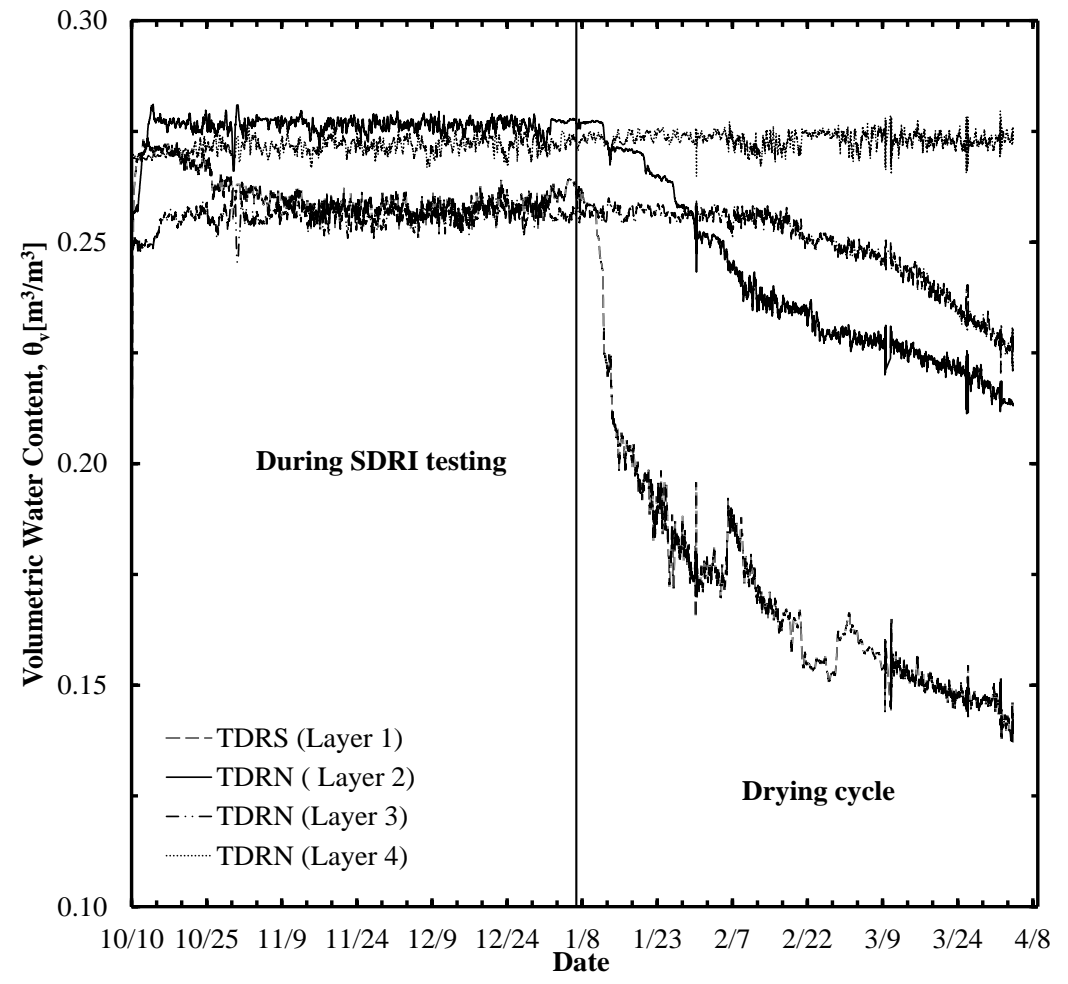

Figure 5. Time-dependent response of the TDR probes located within the compacted clay liner.

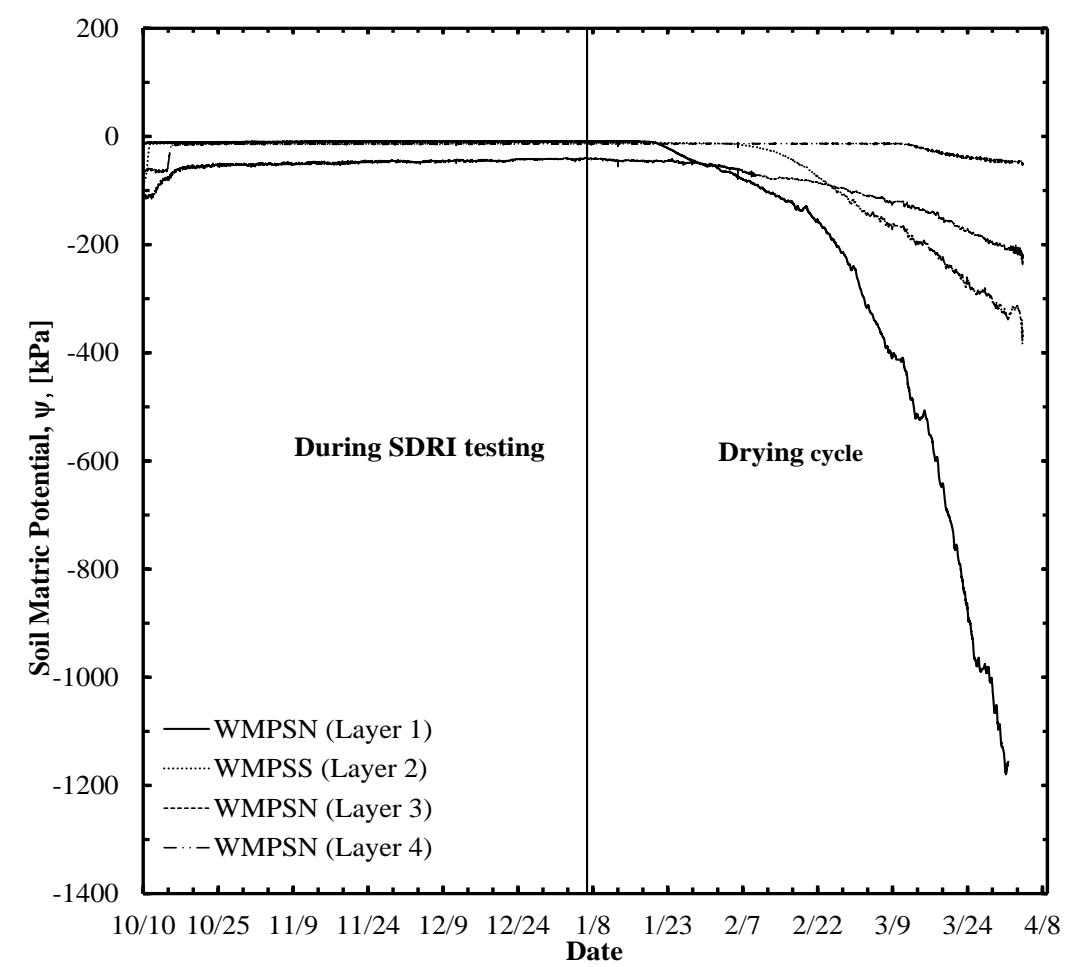

Figure 6. Time-dependent response of the WMPS located within the compacted clay liner. 
The tensiometer probes ( 0 to $-100 \mathrm{Kpa})$ performed better than the WMPS (-10kPa to $3200 \mathrm{kPa}$ ) during wetting because of the range limitations of each of the probes. Specifically, the amount of time required for the wetting front to reach each of the probes was determined by identifying the time when the probes reached a steady maximum value. Ideally, the maximum value for each of the probes should have been zero $\mathrm{kPa}$, however, the maximum value of the WMPS was $-10 \mathrm{kPa}$ and this value was identified to correspond with the arrival of the wetting front. Like with the suction measurements, the amount of time required to reach the maximum volumetric water content was also recorded. The wetting front reached the TDR probes when the maximum volumetric water content was observed.

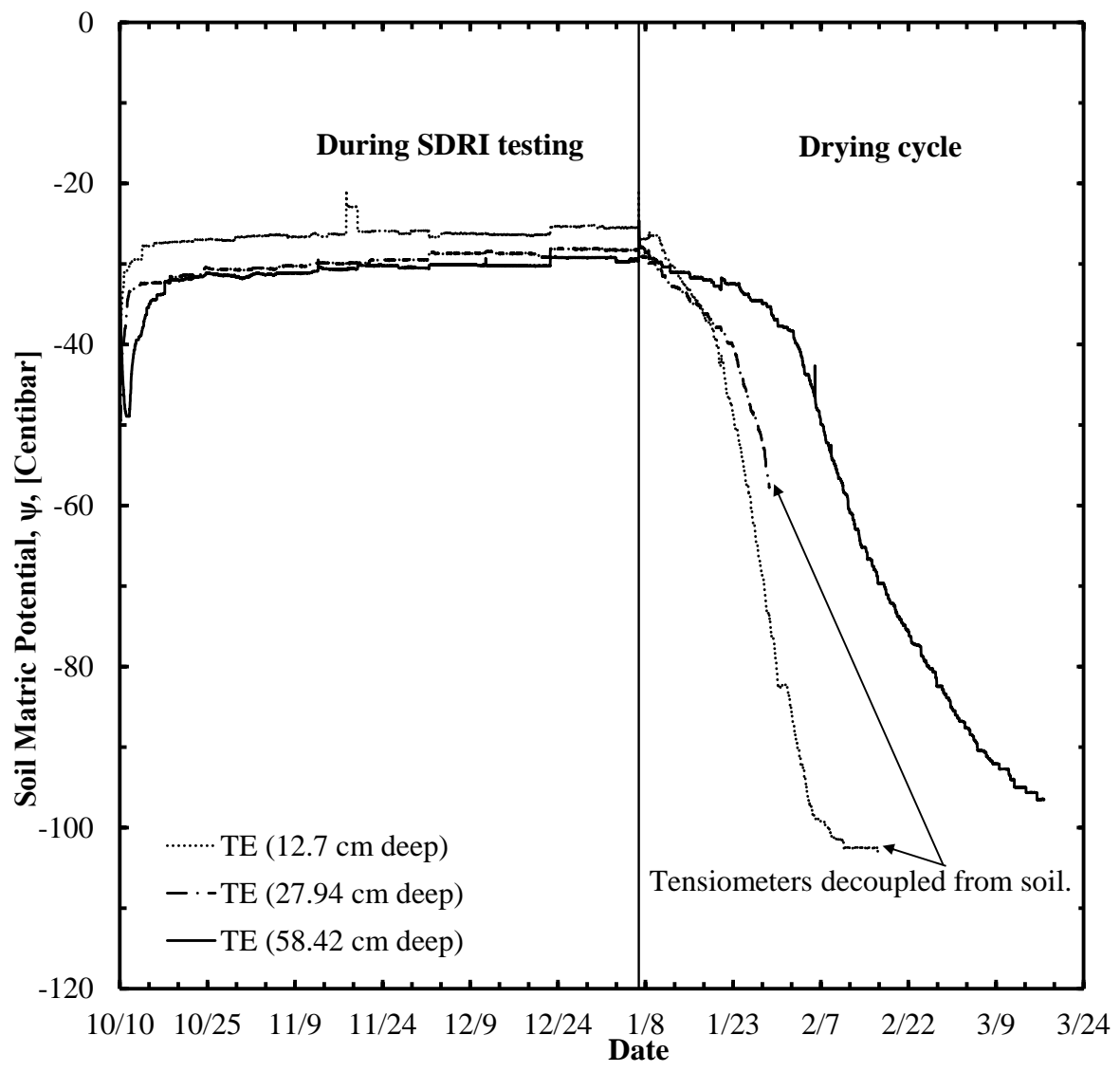

Figure 7. Time-dependent response of the tensiometer probes located within the compacted clay liner. 
The WMPS and TDR probes performed better than the tensiometers during the drying cycle because of the decoupling that was observed to develop between the soil and tensiometer probes. This decoupling phenomenon was only observed for the tensiometers because the casing of the tensiometer probes extended from the surface to the depth of the location of interest, as opposed to the WMPS and TDR probes, where the cable for the probe continued below the surface for some distance before surfacing to connect with the data acquisition system. During the drying cycle, surface cracking propagated along the length of the tensiometer probes and caused the soil to eventually decouple from the probe. The cracks caused a loss of suction and therefore non-representative suction measurements were obtained from the tensiometer probes, following cracking. To ensure accurate measurements during wetting and drying, the use of both types of probes (tensiometer probes and WMPS) is recommended for the respective conditions (wetting and drying).

\subsection{Soil Water Characteristic Cruves}

As shown in Figure 8, the SWCCs that were developed were based on the data obtained from the drying cycle. Although the SWCC is known to exhibit a hysteretic behavior for desorption and sorption, the sorption SWCC was not obtained because the in-situ sensors (TDR probes and WMPS) were not as sensitive to the changes in the soil that were associated with adding water during the SDRI test. The curves begin and end at different values of volumetric water content, because the soil surrounding the probes was first subjected to an infiltration cycle by adding water to the surface of the compacted clay liner and then subjected to a drying cycle by allowing exposure of the surface to atmospheric conditions. Therefore, the soil near the 
surface became saturated faster and dried faster. Also, because the drying front never reached the probes located within the bottom layer, a desorption SWCC was not developed for this layer.

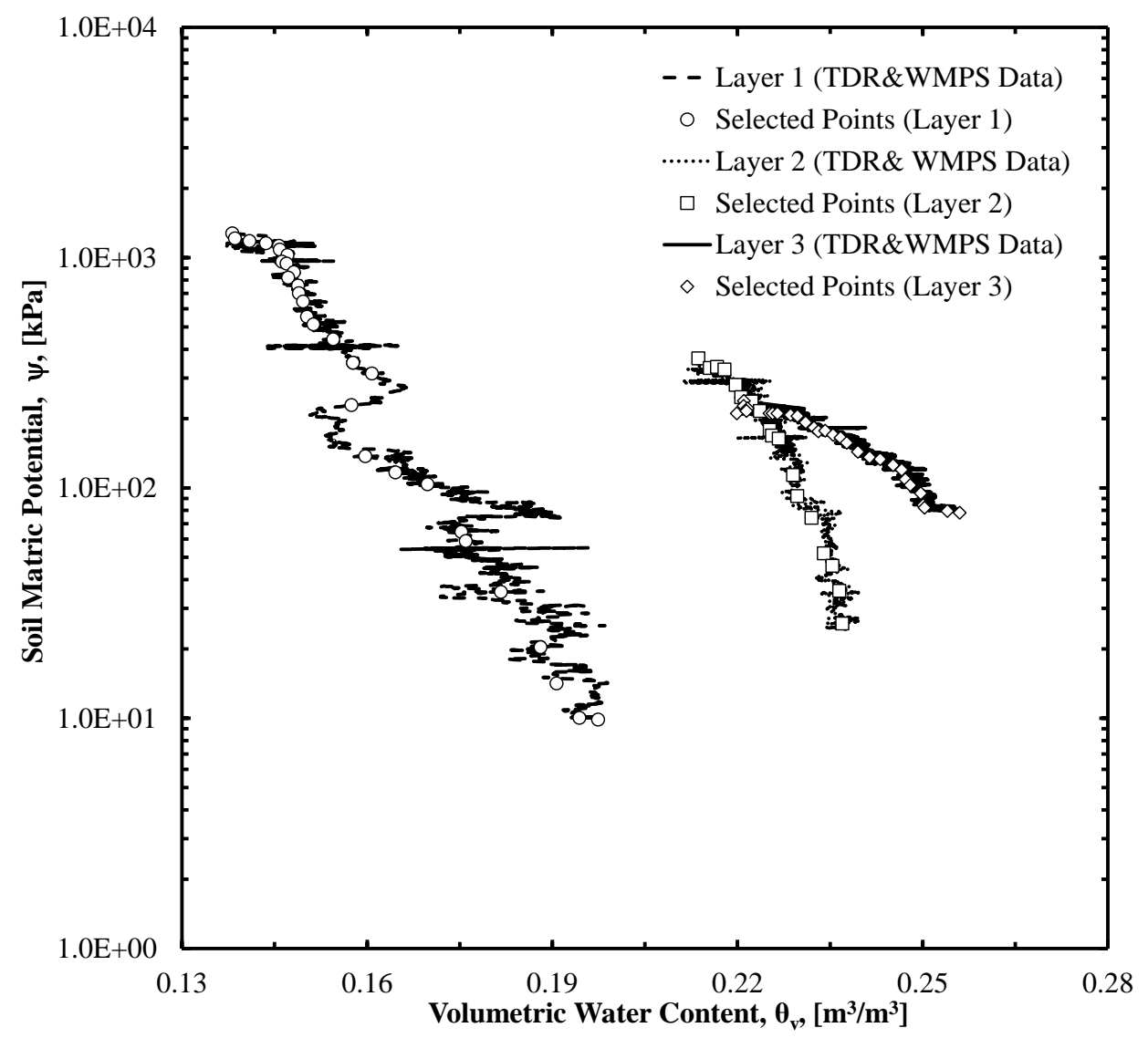

Figure 8. Soil water characteristic curves obtained from the data collected from the TDR and WMPS during the drying cycle (desorption).

Due to the limitation on the amount of data that can be ingested into the RETC program, points were randomly selected from the continuous data (corresponding to the midnight reading on every fifth day). The modeled SWCCs that were developed based on these points are presented in Figure 9. Furthermore, the SWCC curve parameters that were obtained by modeling the data using the van Genuchten (1981) model are also presented in Figure 9. These parameters, the aforementioned geometry of the compacted clay liner and the aforementioned hydraulic conductivity values that were obtained from the FWP were then ingested into the 
UNSAT-H program. The infiltration rate that was calculated from the UNSAT-H program using these parameters is presented in the next section.

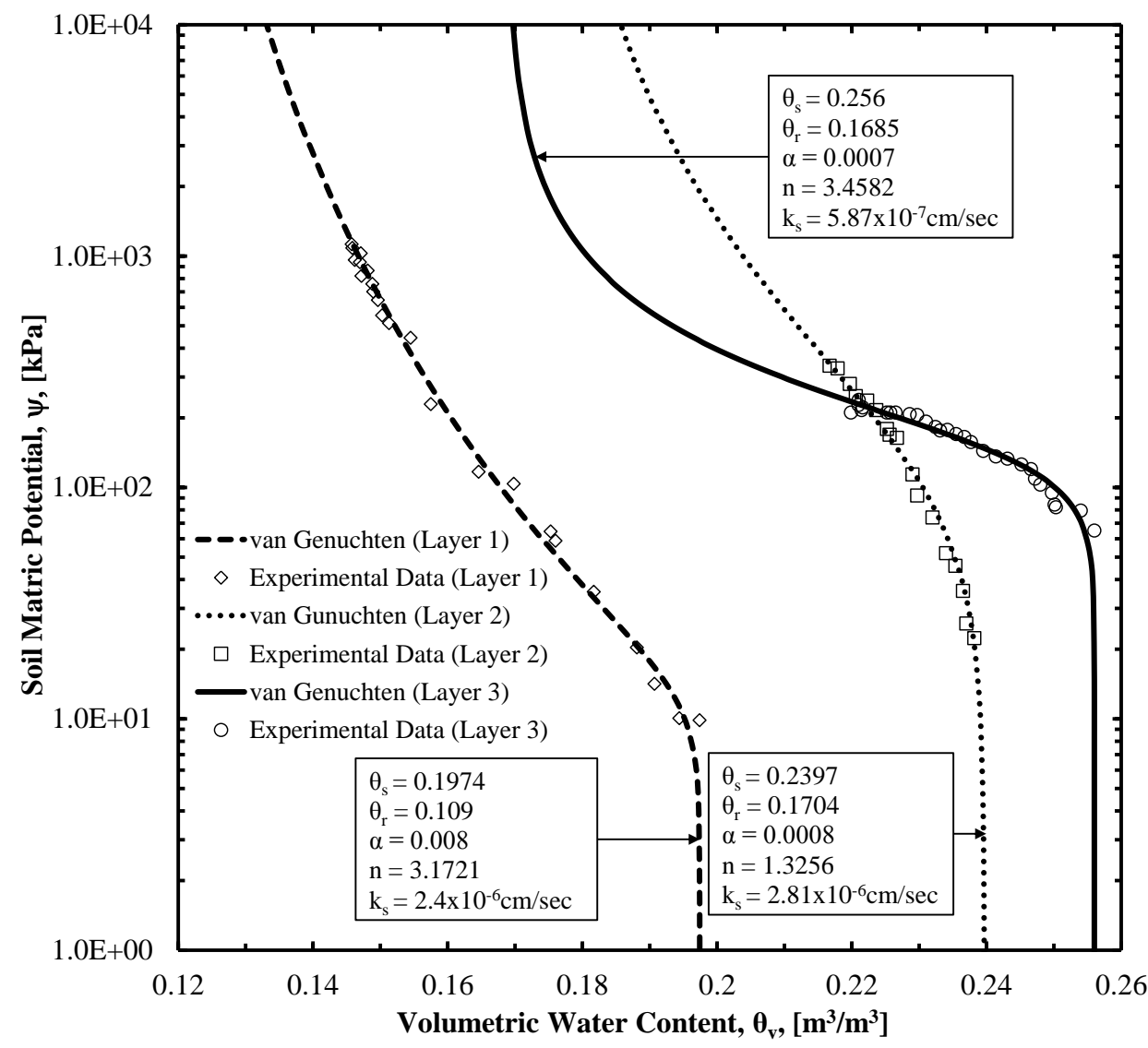

Figure 9. Soil water characteristic curves as modeled from field-obtained data in RETC.

\subsection{Infiltration Rates}

As previously mentioned, the soil hydraulic parameters obtained from RETC were used in UNSAT-H program to simulate the infiltration rate within the compacted clay liner. Because the infiltration rate for the compacted clay liner was predicted using the SWCC that was obtained during the drying cycle,from the in-situ instrumentation, and the k-function was obtained from the FWP samples (Figure 10), the wetting front progressed through the soil faster than predicted (Figure 11). The progression of the wetting front was very dependent on the number of nodal points that were utilized within the UNSAT-H program (Figure 11). When five nodal points 
were utilized (corresponding to the minimum number of points allowed in the UNSAT-H software program), the location of the predicted wetting front moved much faster than the location of the measured wetting front. The predicted solution for the location of the wetting front, as a function of time, converged when 201 nodal points were utilized; however, when 201 node points were utilized the location of the predicted wetting front moved much slower through the soil than the location of the measured wetting front. Specifically, as the number of nodals increases, the wetting front moved slower at any location within the compacted clay liner. The location of the predicted wetting front matched the location of the measured wetting front when 50 nodal points were utilized.

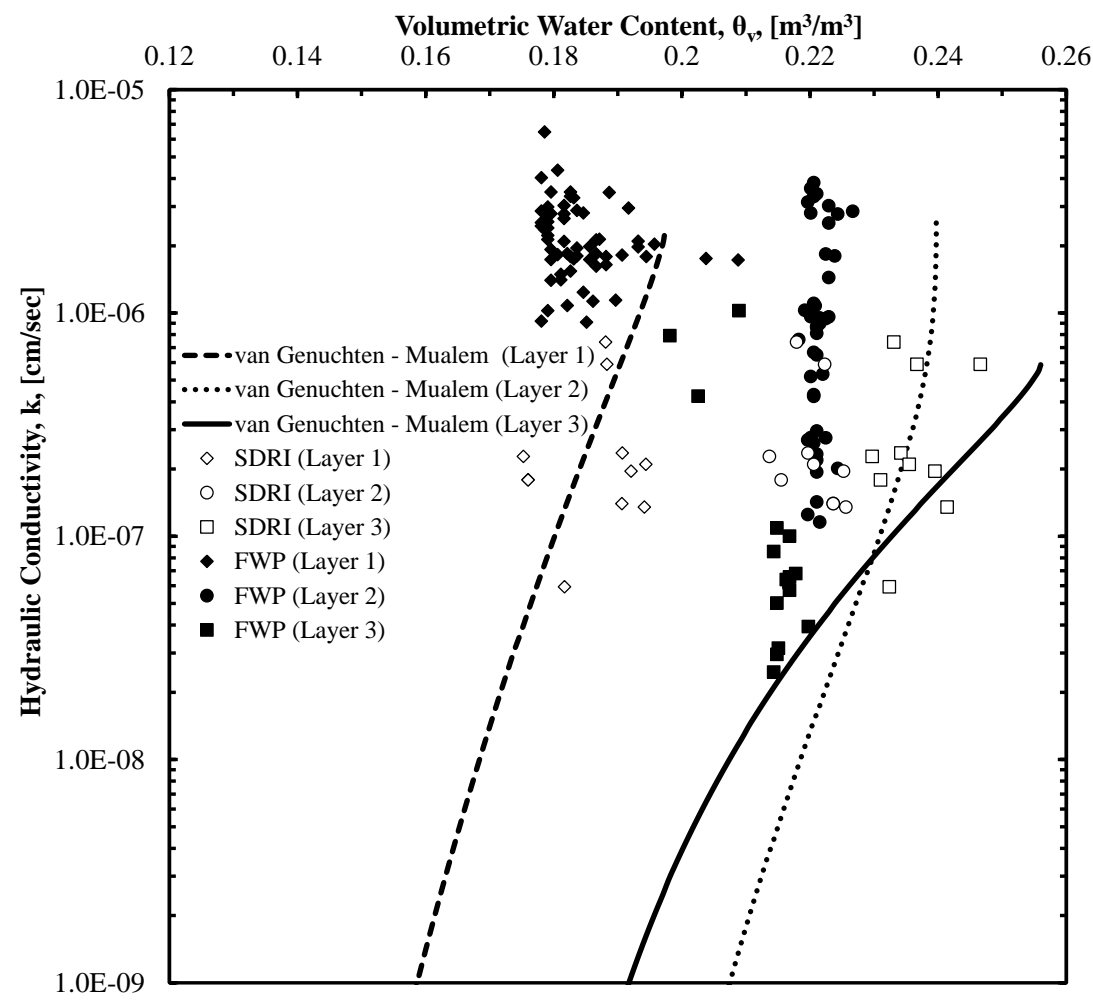

Figure 10. Modeled k-function compared to the k-values obtained from the SDRI and FWP tests.

The rationale for the predicted wetting front moving slower through the soil than the measured wetting front, when a large number of nodes were utilized, was attributed to the 
hysteresis in the SWCC for the sorption/desorption curves. Specifically, for the same value of volumetric water content, a higher value of suction should be measured during desorption than during sorption. Therefore, the wetting front should progress faster following a sorption SWCC than a desorption SWCC. Because the desorption SWCC was utilized to measure the infiltration rate of the soil when subjected to a sorption SWCC the predicted and measured infiltration rates did not correlate. However, although the progression of the wetting front was not well modeled, the k-function was well modeled based on the measured SDRI data (sorption data) bounding the modeled functions (developed using desorption data). The SDRI and FWP data that are presented in Figure 10 were obtained by determining the change in the volume of water within the soil as water was added to the soil during the SDRI and FWP tests.

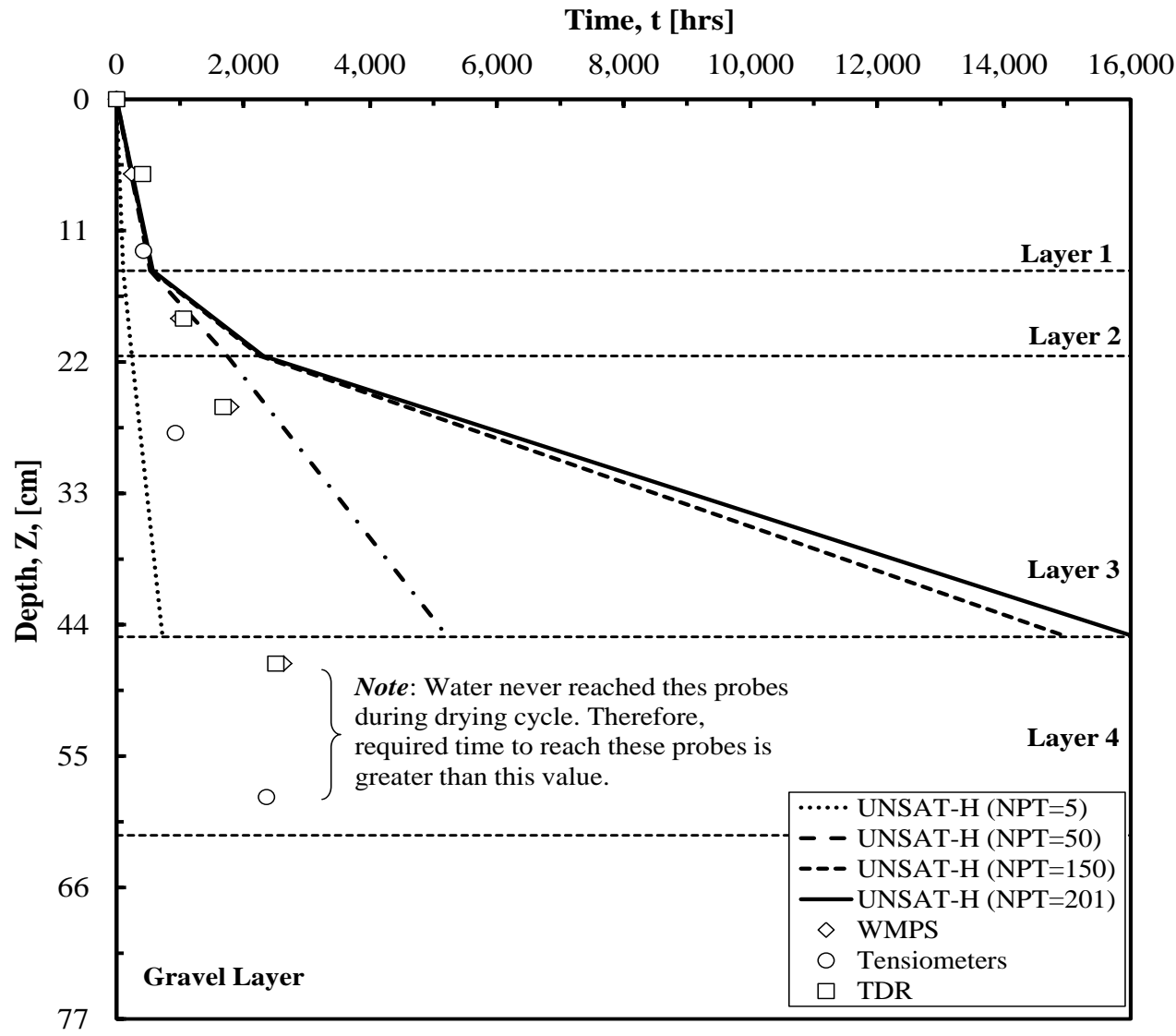

Figure 11. Infiltration rate as measured using field equipment and modeled using the UNSAT-H program. 


\subsection{Field-obtained SWCC Testing Procedure and Results}

As previously discussed, the testing procedures that were utilized may have affected the obtained results. Although the soil utilized in this study was compacted within the previously developed zone of acceptance, that zone of acceptance was originally developed to ensure low permeability values for soils where the water content will remain near the compaction water content; the zone of acceptance was not developed to enable measurement of the SWCC. To obtain both the sorption (wetting cycle) and desorption (drying cycle) data, a new zone of acceptance should be constructed in which the values of compacted water content and dry density should plot on the dry side of the optimum water content instead of on the wet side of optimum water content. However, during compaction of the compacted clay liner that was described herein, the as compacted dry density and water content values plotted near the zero air voids line indicating that the soil in the compacted clay liner was near saturation after compaction. The high levels of saturation were verified by the observed time-dependent values of soil suction and volumetric water content, as obtained during the SDRI testing from the water matric potential sensors and time domain reflectrometery probes, respectively. In addition to the high levels of saturation preventing the acquisition of the sorption SWCC, these levels also led to more intensive desiccation cracking during drying cycle.

Although hydraulic conductivity data from sub-samples of the desiccated soil samples that were collected using the Shelby tubes were utilized to model the infiltration rate through the compacted clay liner, this practice is not advisable. Because of the aforementioned severe desiccation cracking (Figure 12) that was observed to develop within the top layers during the drying cycle; some of the soil samples (sub-samples of the samples acquired from the Shelby 
tubes that were acquired following the drying cycle) that were utilized for the flexible wall hydraulic conductivity were cracked and fissured. These cracks and fissures contributed to the higher values of hydraulic conductivity that may not be representative of soil that is not subjected to a drying cycle.

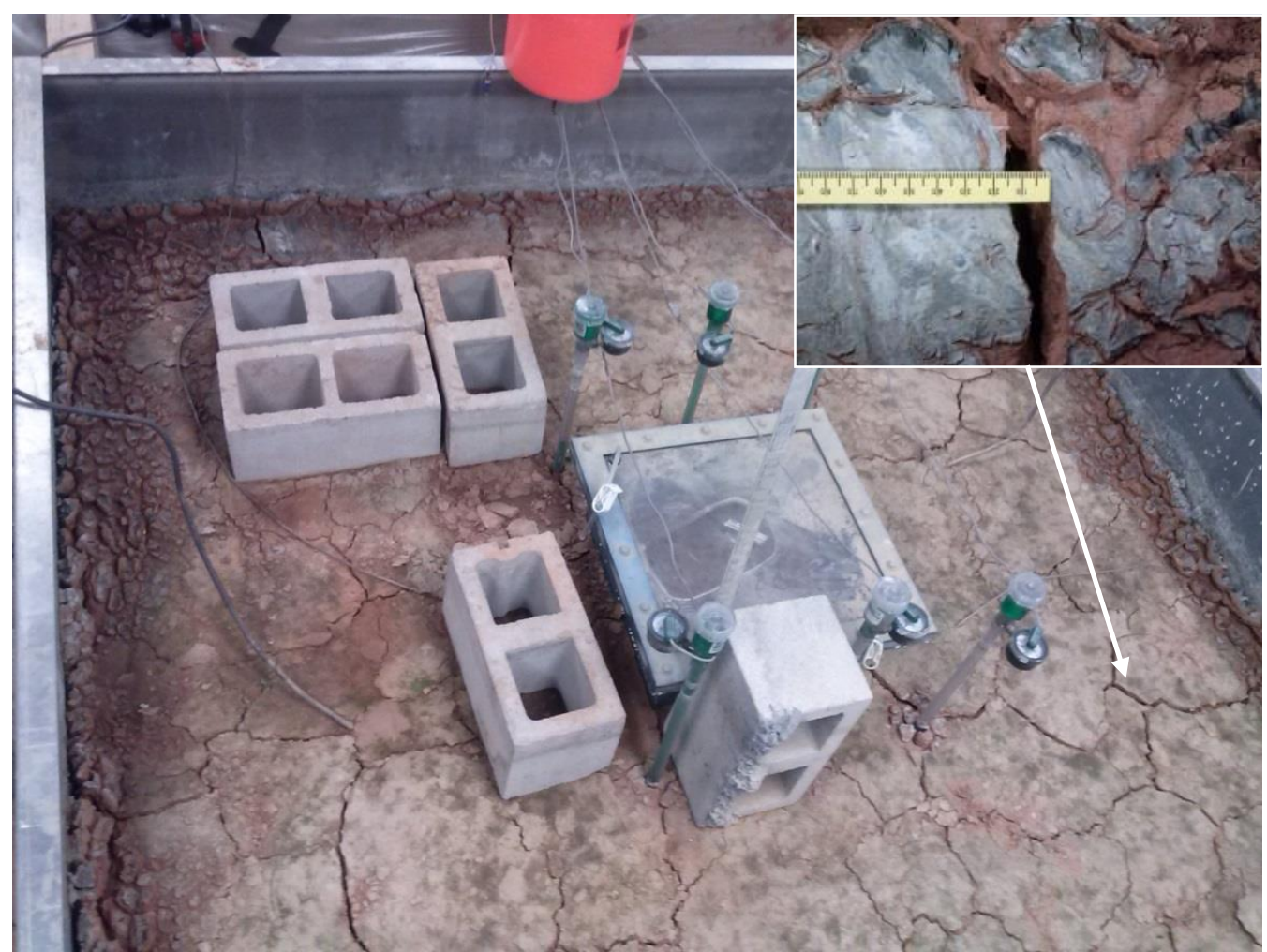

Figure 12. Photograph of desiccation cracking within the compacted clay liner following the drying cycle (picture taken by the author).

Instead, the hydraulic conductivity values that should be utilized within the UNSAT-H program should be obtained from sub-samples collected prior to the drying cycle or from the results obtained from the in-situ tests conducted prior to the drying cycle. Simply put, if samples were collected prior to desiccation then the SWCC and k-function would have been representative of a non-desiccated, saturated or unsaturated clay. However, if desiccation is expected to occur, then the practice of using the permeability values obtained from the 
desiccated samples is advisable, because the SWCC and k-function will be representative of desiccated, saturated or unsaturated clay. The measured hydraulic conductivity values from each layer obtained from SDRI and FWP tests are presented in Table 1 together with the predicted hydraulic conductivity predicted using RETC and UNSAT-H models. Both tests and models approaches agreed reasonably well that as wetted depth increases, the hydraulic conductivity decrease asymptotically.

Table 1. Summary of measured and predicted hydraulic conductivity values.

\begin{tabular}{|l|c|c|c|c|c|c|}
\hline Layers & $\begin{array}{c}\text { Wetting Front } \\
\text { Method }\end{array}$ & $\begin{array}{c}\text { SDRI } \\
\text { Apparent } \\
\text { Method }\end{array}$ & $\begin{array}{c}\text { Suction } \\
\text { Method }\end{array}$ & $\begin{array}{c}\text { FWP } \\
\text { ASTM D5084 } \\
\text { (Method C) }\end{array}$ & $\begin{array}{c}\text { RETC } \\
\text { Mualem (1976) }\end{array}$ & $\begin{array}{c}\text { UNSAT-H } \\
\text { van Genuchten (1980) }\end{array}$ \\
\hline & $\mathbf{k}_{\mathbf{2 0}}$ & $\mathbf{k}_{\mathbf{2 0}}$ & $\mathbf{k}_{\mathbf{2 0}}$ & $\mathbf{k}_{\mathbf{2 0}}$ & $\mathbf{k}_{\mathbf{s}}$ & $\mathbf{k}_{\mathbf{s}}$ \\
\hline & {$[\mathbf{c m} / \mathbf{s e c}]$} & {$[\mathbf{c m} / \mathbf{s e c}]$} & {$[\mathbf{c m} / \mathbf{s e c}]$} & {$[\mathbf{c m} / \mathbf{s e c}]$} & {$[\mathbf{c m} / \mathbf{s e c}]$} & {$[\mathbf{c m} / \mathbf{s e c}]$} \\
\hline Layer 1 & $4.51 \mathrm{E}-07$ & $1.13 \mathrm{E}-07$ & $1.40 \mathrm{E}-07$ & $1.99 \mathrm{E}-06$ & $2.40 \mathrm{E}-06$ & $3.10 \mathrm{E}-06$ \\
\hline Layer 2 & $4.54 \mathrm{E}-07$ & $3.02 \mathrm{E}-07$ & $2.12 \mathrm{E}-07$ & $1.44 \mathrm{E}-07$ & $2.81 \mathrm{E}-06$ & $2.56 \mathrm{E}-06$ \\
\hline Layer 3 & $5.8 \mathrm{E}-08$ & $2.01 \mathrm{E}-07$ & $2.67 \mathrm{E}-08$ & $3.94 \mathrm{E}-08$ & $5.86 \mathrm{E}-07$ & $7.13 \mathrm{E}-07$ \\
\hline
\end{tabular}




\section{CONCLUSION AND RECOMMENDATIONS}

A compacted clay liner was constructed within an environmentally controlled environment to enable collection of SWCCs and k-functions. WMPS, tensiometers, and TDR probes were utilized to measure the amount of suction or volumetric water content within the soil. This instrumentation was also utilized to identify the amount of time required for the wetting front to reach various depths within the soil deposit during a wetting cycle (sorption cycle) that was associated with the 69-day duration SDRI testing. Following SDRI testing, the compacted clay liner was allowed to dry during an 86-day drying cycle. The same instrumentation that was utilized to measure the soil suction and volumetric water content during the SDRI test was also used to measure the soil suction and volumetric water content during the drying cycle and SWCC curves were developed from measured the drying cycle (desorption cycle) data using the RETC program. Shelby tube samples were collected from the compacted clay liner following completion of the drying cycle and FWP tests were performed on subsamples from these Shelby tube samples. The measured hydraulic conductivity values obtained from the FWP tests were used to anchor the k-functions that were created using RETC program.

The RETC developed SWCC and k-functions were ingested into the UNSAT-H program to model how the wetting front progressed through the compacted clay liner as a function of time. Depending on the number of nodal points that were utilized within the UNSAT-H program the predicted location of the wetting front was under-predicted (5 nodal points), predicted (50 nodal points), or over-predicted (200 nodal points) when compared with the measured location (as obtained from the in-situ instrumentation). The over-prediction of the location of the wetting front when using a large number of nodal points (convergence) was attributed to the utilization 
of the desorption SWCC to predict the sorption behavior (due to the inability to measure a sorption curve because the compacted clay liner was compacted on the wet side of the optimum water content). To overcome this discrepancy between the measured and predicted location of the wetting front, the soil should be compacted on the dry side of optimum to enable the measurement of both a sorption and a desorption curve.

Although the predicted location of the wetting front did not match the measured location of the wetting front, the measured k-values obtained from the SDRI test did match the predicted k-values. However, the measured k-values were higher than the regulatory limit even though the compacted clay liner was compacted within the zone of acceptance that was developed to ensure that the saturated k-values were below the regulatory limit. The high k-values obtained from the FWP were believed to be attributed to desiccation cracking while the high k-values obtained from the SDRI were believed to be attributed to several of the measured dry density/water content points plotting outside of the zone of acceptance.

It is recommended that the soil be compacted on the dry side of the optimum water content to overcome the difficulty of predicting the location of the wetting front during sorption using a desorption obtained SWCC, and to overcome the severe desiccation cracking that occurs during drying. Specifically, if the soil is compacted on the dry side of the optimum water content, then a sorption SWCC can be developed during the SDRI testing and a desorption SWCC can be developed following the SDRI testing during the drying cycle. The data collected during the sorption SWCC can then be utilized to predict the location of the wetting front during the SDRI test. 


\section{REFERENCES}

American Society for Testing and Materials (2012), "Standard Test Methods for Determination of the Soil Water Characteristic Curve for Desorption Using a Hanging Column, Pressure Extractor, Chilled Mirror Hygrometer, and/or Centrifuge." Annual Book of ASTM Standards, Designation D6836, Vol.4.08, ASTM, West Conshohocken, PA.

American Society for Testing and Materials (2012), "Standard Test Methods for Measurement of Hydraulic Conductivity of Saturated Porous Materials Using a Flexible Wall Permeameter" Annual Book of ASTM Standards, Designation D5084, Vol. 4.08, ASTM, West Conshohocken, PA.

American Society for Testing and Materials (2012), "Standard Test Methods for Field Measurement of Infiltration Using Double-Ring Infiltrometer with Sealed-Inner Ring "Annual Book of ASTM Standards, Designation D5093, Vol. 4.08, ASTM, West Conshohocken, PA.

Beese, F., and van der Ploeg, R. R. (1976). "Influence of hysteresis on moisture flow in an undisturbed soil monolith.” Soil Sci. Soc. Am. J., 40, 480-484.

Brooks, R., and Corey, A. (1964). "Hydraulic properties of porous media." Hydrology paper 3 Colorado State University, Fort Collins, CO.

Campbell Scientific, Inc., (2009). "229 Heat Dissipation Matric Water Potential Sensor" Instruction manual.

Campbell Scientific, Inc., (2013). "TDR Probes CS 605, CS610, CS630, CS635, CS640, CS645.” Instruction manual.

Darcy, H. (1856). Les Fontainines Publiques de la Ville de Dijon, Dalmont, Paris. 647pp.

Day, S., and Daniel, D., (1985). "Hydraulic Conductivity of Two Clay Prototype Clay Liners." Journal of Geotechnical Engineering, ASCE, Vol. 111, No. 8, pp. 957-970.

Fredlund, D. and Xing, A. (1994). "Equations for the Soil-Water Characteristic Curve." Canadian Geotechnical Journal. Vol. 3, No. 4, pp. 533-546.

Fredlund, D. G. and Rahardjo, H. (1993). “ Soil Mechanics for Unsaturated Soils.” John Wiley and Sons Inc., New York.

Fedlund, D.G. (1995). "Prediction of unsaturated soil functions using the soil-water characteristic cuver." Unsaturated Soils Group Department of Civil Engineering. University of Saskatchewan, 57 Campus Drive. Canada. 
Fedlund, M. D., Sillers, W. S., Fredlund, D. G. and Wilson, G. W. (1996). "Design of a knowledge-based system for unsaturated soil properties. In Proceedings of the CanadianConference on Computing in Civil Engineering, Mont-real, Quebec, August 2628:659-677.

Fernando A. M. Marinho (2005). "Nature of soil-water characteristic curve of plastic soils." Journal of Geotechnical and Geoenvironmental/ Engineering, ASCE. Vol.131, No. 5.

Garner, C.D., Coffman, R.A., (2014) "Remotely Sensed Volumetric Water Content and Dry Density Utilizing Change Detection, Polarimetric, and Interferometric Methods." Journal of Geotechnical and Geoenvironmental Engineering. Submitted for Review, Manuscript Number GTENG-3926.

Klute, A., G.S.Campbell, R. D. Jackson, M.M. Mortiland, and D.R. Nielson. (1986). "Methods soil analysis. Part 1. Physical and Mineralogical Methods, Second Edition. American Society of Agronomy and Soil Science of America, Madison, Wisconsin, $810 \mathrm{pp}$.

Li, A. G., Tham, L. G., Yue Z. Q., Lee, C. L., and Law K. T. (2004). “Comparison of field and Laboratory soil-water characteristic curves." Journal of Geotechnical and Geoenvironmental/ Engineering, ASCE. Vol.131, No. 9.

Lu, N. and Likos, W.J. (2004a). “Unsaturated Soil Mechanics.”John Wiley\& Sons, New Jersey, USA. P.556.

Lu, N., and Kaya, M., (2013).”A drying cake method for measuring suction stress characteristic curve, soil-water retention, and hydraulic conductivity function." Geotechnical Testing Journal, 36, 1-19, doi:10.1520/GTJ20120097

Lu, N. and Likos, W.J. (2006). "Suction stress characteristic curve for unsaturated curve for unsaturated soil." Journal of Geotechnical and Geoenvironmental/ Engineering, ASCE. Vol.132, No. 2.

Lu N., Kaya.M., and Godt. W. J (2014). "Interrelations among the Soil-Water Retention, Hydraulic Conductivity, and Suction-Stress Characteristic Curves. Journal of Geotechnical and Geoenvironmental/ Engineering, ASCE, ISSN 1090-024/04014007.

Menziani, Marilena Maria Rosa Rivasi, Sergio Pugnaghi, Renato Santangelo and Sergio Vincenzi (1996). "Soil Volumetric Water Content Measurements Using TDR technique.”Annali Di Geofisica, Vol. XXXIX, No.1.

Meerdink, J. S., Benson, C. H., and Khire, M. V. (1996). "Unsaturated hydraulic conductivity of two compacted barrier soils." Journal Geotechnical Engineering, ASCE, 122(7), 556-576. 
Mijares R.G.,and Milind V. Khire (2010). "Soil water characteristic cruves of compacted subjected to multiple wetting and drying cycles." GeoFlorida 2010: Advances inAnalysis, Modeling \& Design.

Moore, R. E. (1939). "Water conduction from shallow water tables." Hilgardia, 12, 383-426.

Nanak, Matthew J., (2012). "Variability in the Hydraulic Conductivity of a Test Pad Liner system Using Different Testing Techniques.” Master's Thesis, University of Arkansas, May.

Nemmer, Charles, (1998). "Volumetric Moisture Content Using Time Domain Reflectrometry."FHWA publication number: FHWA-RD-139.

Ogorzalek A. S., Bohnholf G.L., Shackelford C. D., Benson, C. H., and Apiwantragoon (2008)."Compaction of field data and water-balance predictions for a capillary barrier covers."Journal Geotechnical Engineering, ASCE. Vol. 134 No. 4.

Olson, R. E., and Daniel, D. E., (1981). "Measurement of hydraulic conductivity of fine-grained soil." In Zimmie, T.F., and Riggs, C.O. (Eds.) Permeability and Groundwater Contaminant Transport. ASTM Spec. Tech. Publ., 746:18-64.

Paker, J.C., Kool, J. B., and van Genuchten, M. Th. (1985). "Determining soil hydraulic soil properties from one-step outflow experiments by parameter estimation:II. Experimental studies." Soil Sc.Soc. Am. J., 49(6), 1353-1359.

Phene C., Rawlins, S., Hoffman, G., (1971). "Measuring Soil Matric Potential In situ by Sensing Heat Dissipation within a Porous Body: I. Theory and Sensor Construction." SoilScience Society of America Journal. Vol.35, pp.27-33.

Reece, C.F. (1996). "Evaluation of a line heat dissipation sensor for measuring soil matricpotential. Soil Sci. Soc. Am. J. 60: 1022-1028.

Reginato, R. J., and R. D., Jackson., (1971a). “Field measurement of soil-water content by gamma-ray transimission compensated for temperature fluctuations." Soil Sci. Soc. Amer. Proc. 35: 529-533.

Ridley, A., Marsland F., and Patel A., (1998). "Tensiometers: their design and use for civil engineering purposes." Geotechnical Site Characterisation: Proc. $1^{\text {st }}$ internationalConference on Site Characterization, Atlanta, USA. (Ed. P.K Robertson \& P.W Mayne), Vol 2, pp. 851-856.

Sillers, W. S., Fredlund, D. G., and Zakerzadeh, N. (2011). "Mathematical attributes of some soil-water characteristic curve models." Geotechnical Geology Engineering, 19(3-4), 243-283. 
Evett S. R. (2003). "Soil water measurement by Time Domain Reflectrometry.” Conservation and Production Research Laboratory, USDA-ARS. P.O. Drawer 10, Bushland, Texas, USA.

Take, W., and Bolton, M., (2003). "Tensiometer saturation and reliable measurement of soil suction." Geotechnique, Vol.53, No.2, pp. 159-172.

Tinjum M.J., Benson C., and Blotz R.L., (1997). "Soil-Water Characteristic Curves for Compacted Clays.” Journal of Geotechnical and Geoenvironmental Engineering, ASCE. Vol. 123, No. 11.

Thu, T.M., Rahardjo, H., and Leong, E. C. (2007). " Soil-water characteristic curve and consolidation behavior for a compacted slit." Cana. Geotechnique. J., Vol.44, 266-275.

Topp, G. C., and E. E. Miller, (1966). “ Hysteresis moisture characteristics and hydraulic conductivities for glass-bead media." Soil Sci. Soc. Amer. Proc., 30, 156-162.

Trautwein, S. and Boutwell, G. (1994). "In situ hydraulic conductivity tests for compacted soil liners and caps." Hydraulic Conductivity and Waste Contaminant Transport in Soil, STP 1142, D. Daniel and S. Trautwein, eds., ASTM, Philadelphia, pp. 184-223.

Trautwein Soil Testing Equipment Co. (1987). "Installation and operating instructions for the sealed double-ring infiltrometer.’Trautwein Soil Testing Equipment Co., Houston, TX.

Tzimas, E. (1979). "The measurement of soil water hysteretic relationship on a soil monolith.” J. Soil Sci., 30, 529-534.

Vanapalli, S. K., Fredlund, D. G., and Pufahl, D. E (1999). "The influence of soil structure and stress history on the soil-water characteristics of a compacted till."Geotechnique, 49(2), 143-159.

van Genuchten, M. T. (1980). "A closed-form equation for predicting the hydraulic of unsaturated soils." Soil Science American Journal. 44(5), 892-898.

Wang, X., and Benson, C. (2004).'Leak-free pressure plate extractor for measuring the soil water characteristic curve." Geotechnical Testing Journal 27(2), 1-10.

Watson, K.K., Reginato, R. J., and Jackson, R. D. (1975). "Soil water hysteresis in a field soil." Soil Sci. Soc. Am. Proc., 39, 242-246.

Wayllace, A., and Lu, N. (2012). "A transient water release and imbibitions method for rapidly measuring wetting and drying soil water retention and hydraulic conductivity functions."Journal ASTM Geoetechnical Test., 35(1), 1-15. 


\section{APPENDIX A. DISCUSSIONS}

\section{Discussion on Zone of Acceptance and Nuclear Gauge Density Testing Results}

As previously mentioned, a zone of acceptance (ZOA) was developed by Nanak (2012) following Daniel and Benson (1990) method was used in this study (Figure 4). The methods and discussion describing the development of the zone of acceptance are described in Nanak (2012). To ensure the quality of construction to meet the requirements, a rod and level were utilized to check the height and the elevations of each lift, and the proper compaction was verified using a nuclear density gauge data (ASTM D6938), and four readings were taken at four different locations on the top of each layer. The locations of each nuclear density gauge test are illustrated in Figure 13. The nuclear density gauge tests were conducted outside of the outer ring of SDRI to avoid any soil disturbance in the testing area. The results obtained during nuclear density gauge testing in each layer are also summarized in Table 2.

The results obtained from nuclear density gauge testing are also presented in the plot of zone of acceptance (Figure 4). As shown in Figure 4, most of the points plotted inside the of the ZOA expect the three points from layer 4 , one data points from layer 3 and one data point from layer 2. In layer 4, a different method of adding water into the soil was used prior the soil placement. As a result, low water contents and higher unit weights were obtained after compaction. Typically, when nuclear gauge density tests results are plotted outside of the ZOA, the layer is removed and reworked. However, the soil in layer 4 was not reworked because the tests were completed outside of the area of interest for SDRI testing. 


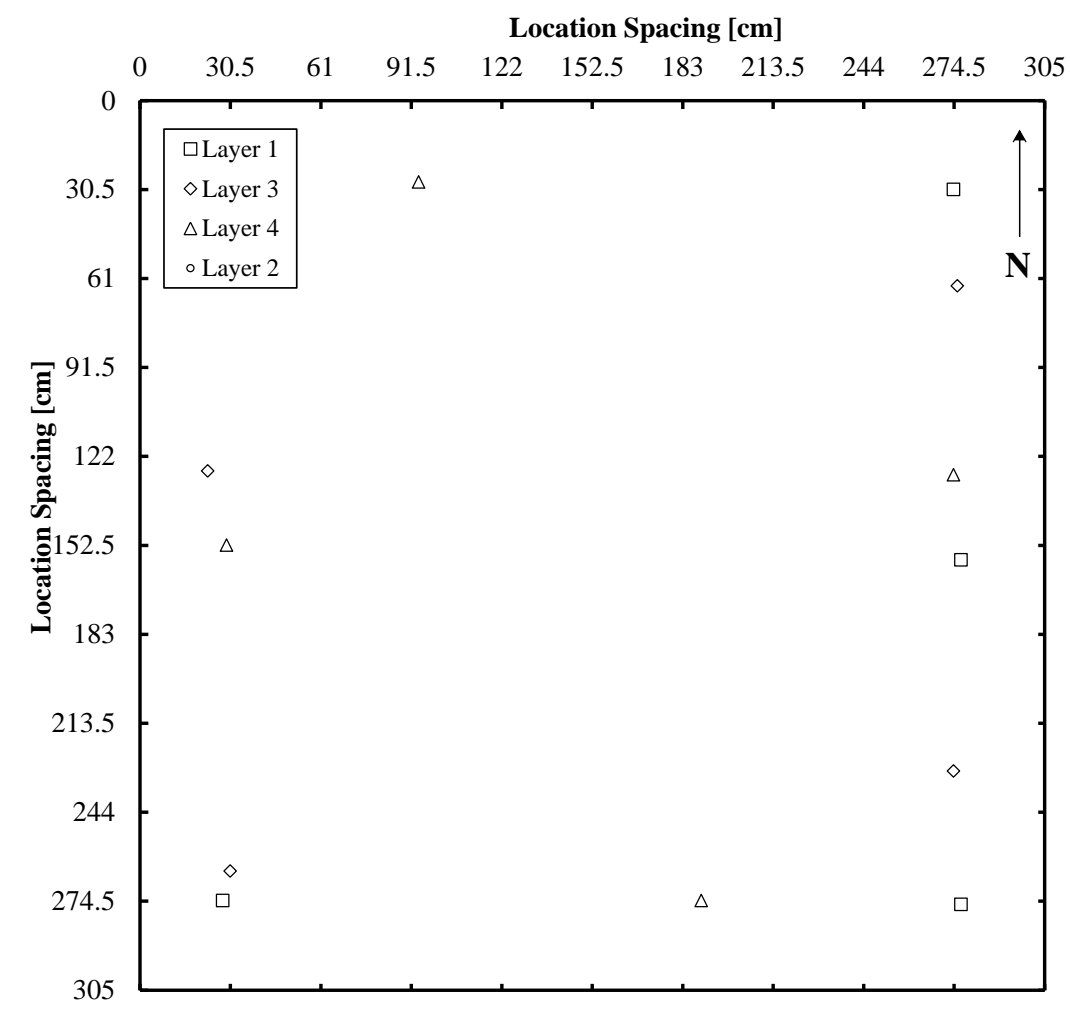

Figure 13. Nuclear density gauge testing locations.

Table 2. Results of nuclear density gauge data.

\begin{tabular}{|c|c|c|c|c|}
\hline \multirow{2}{*}{ Layers } & Distance to S & Distance to W & Dry Unit Weight & Water Content \\
\cline { 2 - 5 } & & & $\boldsymbol{\gamma}_{\text {dry }}$ & $\boldsymbol{w}$ \\
\cline { 2 - 5 } & {$[\mathbf{c m}]$} & {$[\mathbf{c m}]$} & {$[\mathbf{p c f}]$} & {$[\%]$} \\
\hline Layer 1 & 274 & 27.94 & 96.01 & 26.76 \\
\hline Layer 1 & 275.59 & 276.86 & 98.65 & 24.88 \\
\hline Layer 1 & 157.48 & 276.86 & 97.96 & 25.23 \\
\hline Layer 1 & 30 & 274 & 99.21 & 23.88 \\
\hline Layer 2 & 27.94 & 78.74 & 91.79 & 20.15 \\
\hline Layer 2 & 279.40 & 73.66 & 100 & 22 \\
\hline Layer 2 & 274 & 241.30 & 100.3 & 20.98 \\
\hline Layer 2 & 61 & 274 & 102.3 & 19.74 \\
\hline Layer 3 & 22.86 & 127.00 & 97.12 & 20.9 \\
\hline Layer 3 & 30 & 264.16 & 102.4 & 20.24 \\
\hline Layer 3 & 274 & 229.87 & 102.1 & 21.49 \\
\hline Layer 3 & 275.59 & 63.50 & 97.25 & 22.25 \\
\hline Layer 4 & 27.94 & 93.98 & 102.7 & 17.08 \\
\hline Layer 4 & 274 & 189.23 & 106.5 & 18.75 \\
\hline Layer 4 & 152 & 29.21 & 106.7 & 19.26 \\
\hline Layer 4 & 128.27 & 274 & 100.2 & 22.25 \\
\hline & & & & \\
\hline
\end{tabular}


As described in the chapter 3, the soil was placed into four compacted layers. The thicknesses of each layer were measured using a rod and level. In addition, WMPS and TDR probes were installed within each layer below in the inner ring as shown in Figure 1 and 2. The thicknesses of each layer and the locations of the all probes in each layer are presented in Table 3 and 4, respectively. During the surveying on layer 3, the gravel layer thickness placed at the bottom of the test pad was not taken into consideration while measuring the minimum thickness of loose layer. Consequently, layer 3 was determined to be thicker than other layers, and layer 2 was thinner than other layers in the test pad.

Table 3. Summary of layers thicknesses.

\begin{tabular}{|c|c|}
\hline Layers & Thickness \\
\hline & {$[\mathbf{c m}]$} \\
\hline Layer 1 & 14.36 \\
\hline Layer 2 & 7.15 \\
\hline Layer 3 & 23.50 \\
\hline Layer 4 & 16.63 \\
\hline Total Clay thickness & 61.64 \\
\hline
\end{tabular}

Table 4. TDR and WMPS locations.

\begin{tabular}{|l|c|}
\hline Layers & TDR \&WMPS Location \\
\hline & {$[\mathbf{c m}]$} \\
\hline Layer 1 & 6.26 \\
\hline Layer 2 & 18.37 \\
\hline Layer 3 & 25.76 \\
\hline Layer 4 & 47.25 \\
\hline
\end{tabular}




\section{Discussion on In-situ Hydraulic Conductivity Results Obtained Using SDRI test}

As described in the Chapter 4, the SDRI test was conducted for 69 days and 15 hours. Following the procedures and the methods of data reduction documented in ASTM D5093, the vertical hydraulic conductivity values were determined. The infiltration rates for each timed interval were first calculated. Higher infiltration rates were observed in layer 1 because the soil was compacted on low water content with higher unit weights as discussed above. In addition, high infiltration rates were observed when the water added in the IV bag, this was caused by the change of volume of flow. The data recorded during SDRI testing is summarized in Table 5 and the infiltration rate results are presented in Table 5 and plotted in Figure 14.

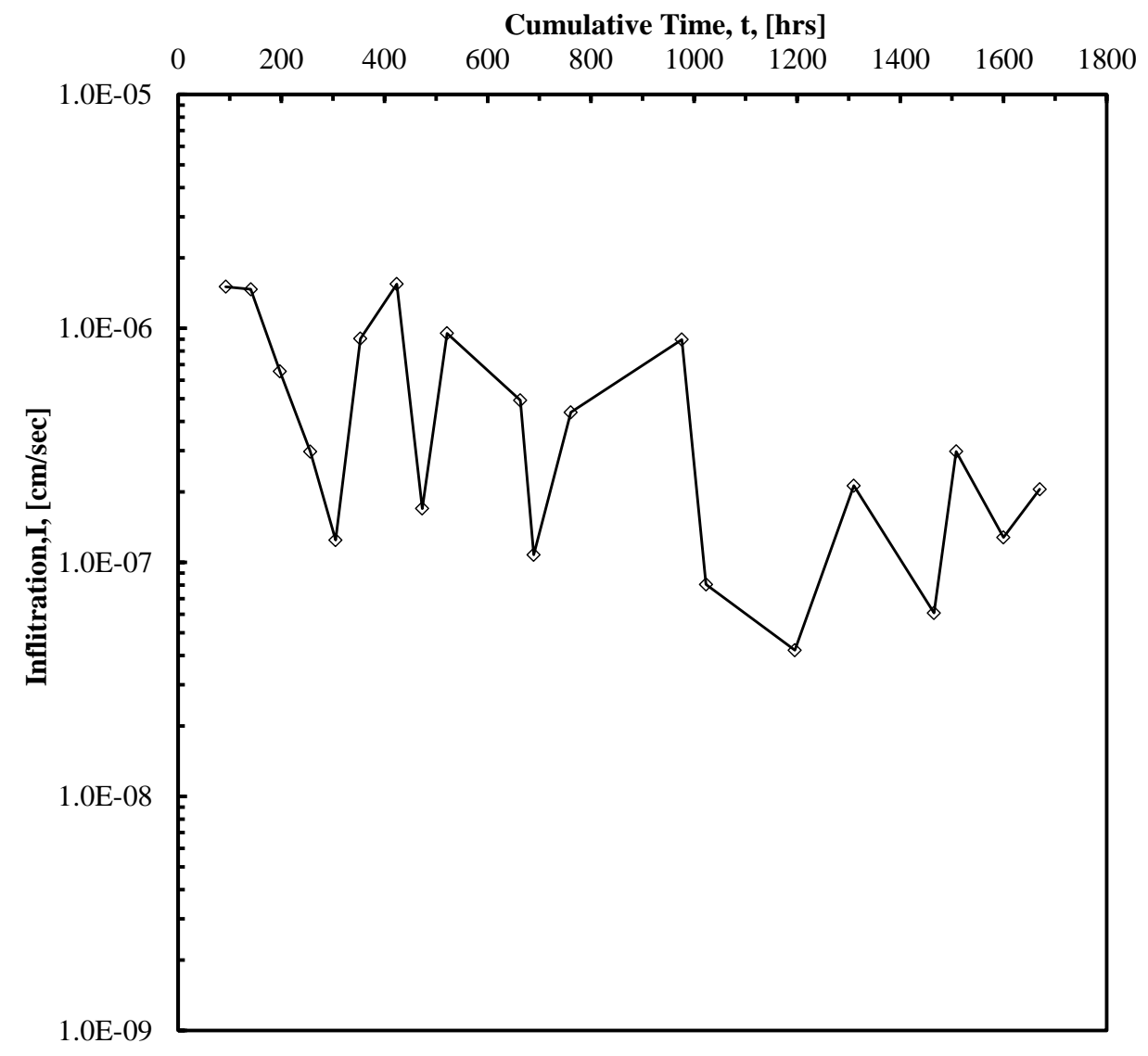

Figure 14. Summary of infiltration and cumulative time obtained during SDRI testing 
The irrometer tensiometers installed were used to monitor the progression of the wetting front during SDRI testing. The tensiometer results are summarized in Figure 7. Higher soil suctions were observed at the start of the test and started to decrease asymptotically as the water penetrates into the soil. The wetting front was located when the water reached the porous tip of the tensiometers. As shown in Figure 15, water reached the porous tip of the tensiometers located at $12.7 \mathrm{~cm}, 27.94 \mathrm{~cm}$ and $58.42 \mathrm{~cm}$ at 353.22 hours, 857.25 hours and 1670.12 hours, respectively. These three points plotted in Figure 14 were used define a linear equation to determine the location of the wetting front at any given time.

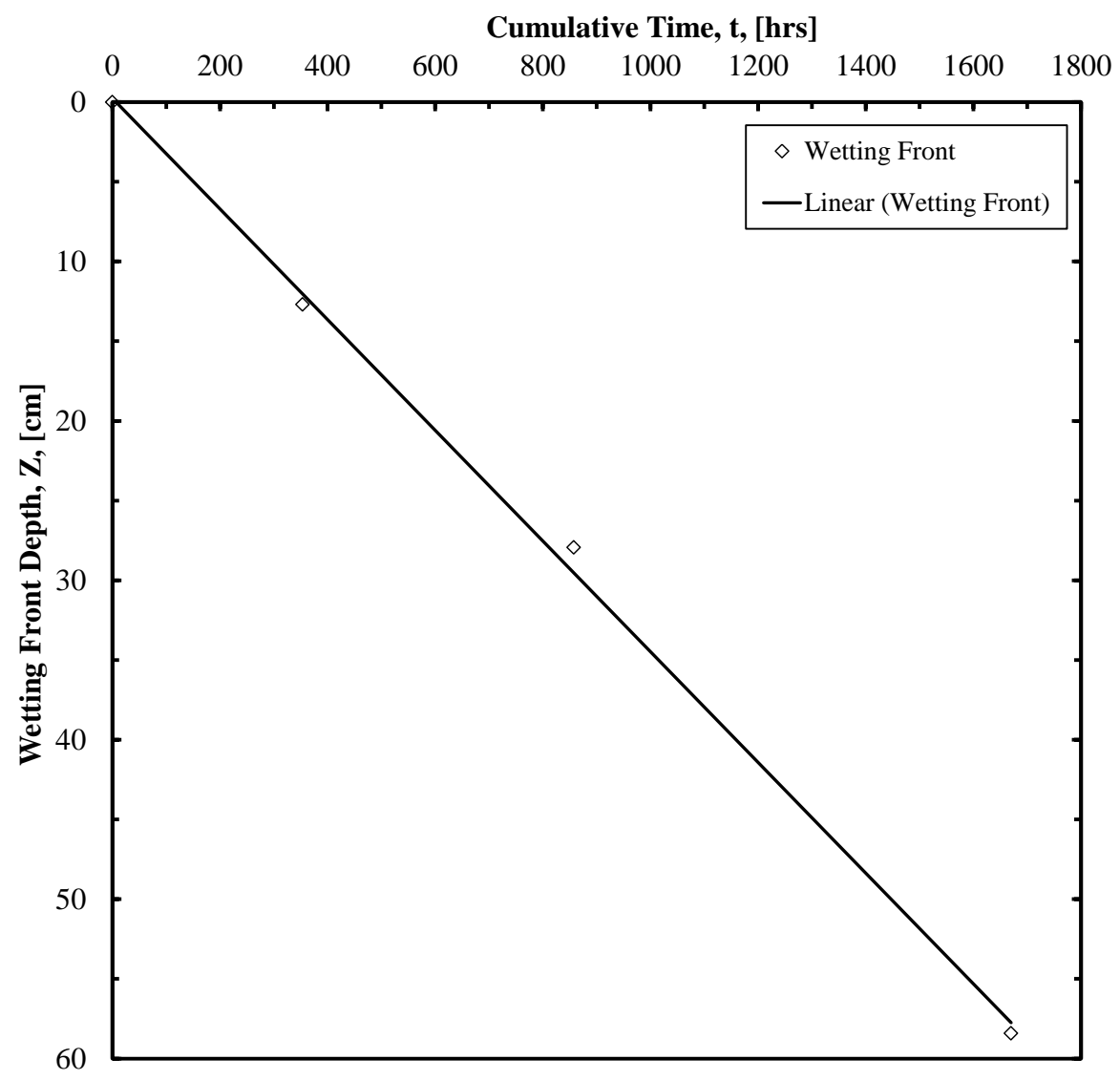

Figure 15. Summary of wetting front location during SDRI testing. 
The wetting front locations were necessary needed to calculate the hydraulic gradient $(i)$.

The hydraulic gradients were determined using three methods (Apparent Hydraulic

Conductivity, the Suction Head, and the Wetting Front Method) proposed by Trautwein and

Boutwell (1990) and discussed into details by Nanak (2012). The results of hydraulic gradients are presented in Table 6 and also summarized in Figure 16. Higher hydraulic gradients were determined using suction head method and constant gradients were observed using apparent method. The calculated infiltration rates and hydraulic gradients were used to determine the hydraulic conductivity of the soils. The results are presented in Chapter 4.

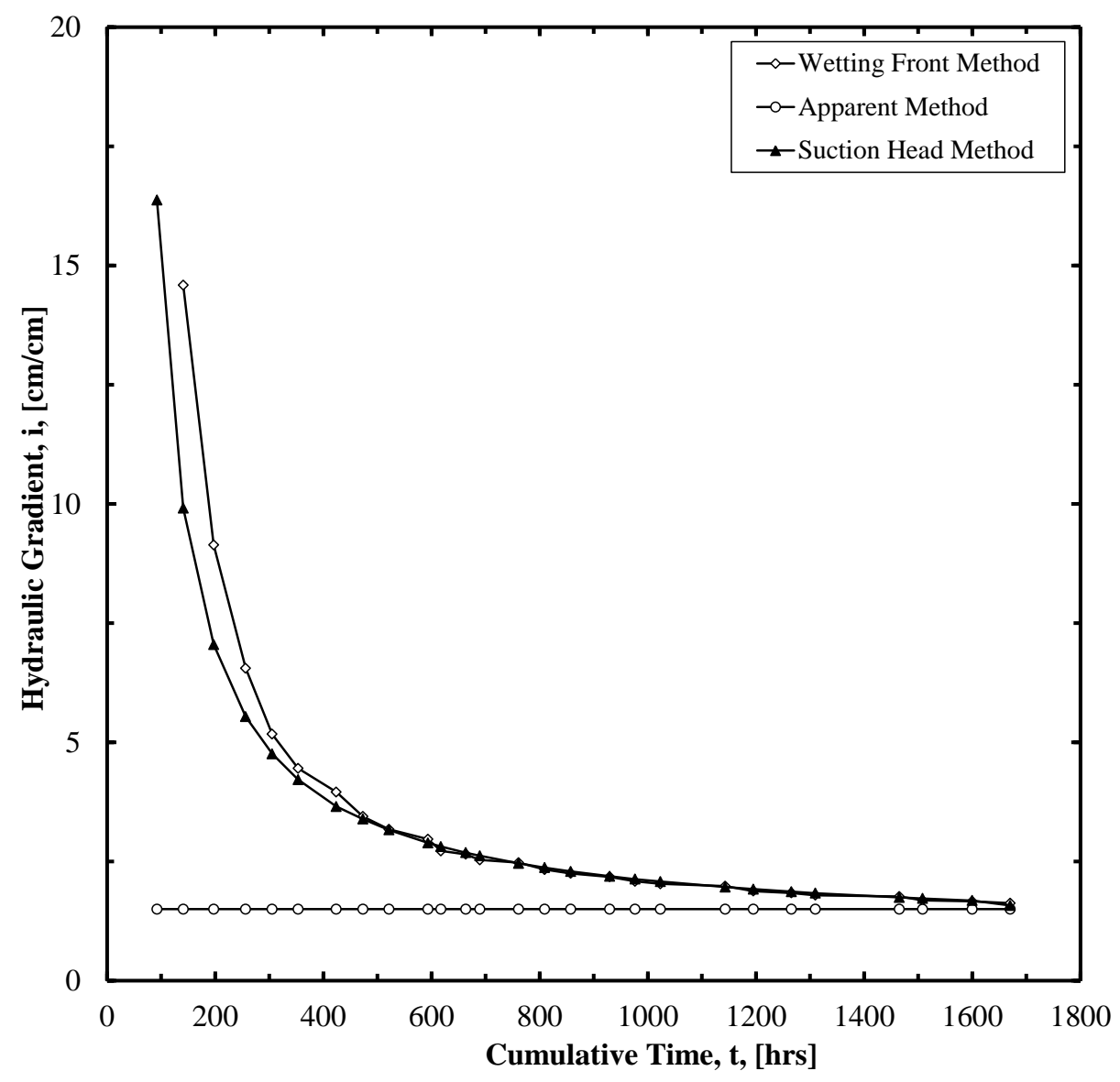

Figure 16. Summary of hydraulic gradient and cumulative time obtained during SDRI testing. 


\section{Discussion on Laboratory Hydraulic Conductivity Results Obtained Using FWP Tests}

Following the procedures documented in ASTM D5084 for data reduction, the laboratory hydraulic conductivity of the soil used in this research study was determined. The flexible wall permeameter tests were conducted on the samples extruded from the Shelby tubes. Specifically, four samples (one sample in each layer) with an approximate of $7.62 \mathrm{~cm}$ for both diameter and height were extruded from the Shelby tubes. Note that, the Shelby tubes were collected after drying cycle. Consequently, higher hydraulic conductivities were anticipated to be observed comparing to the SDRI results. From the laboratory results, high hydraulic conductivity values were observed on the sample obtained from Layer 1, and low hydraulic conductivity values on sample obtained from Layer 4 because water contents in layer 4 were higher than within other layer. The FWP tests were conducted until the measured hydraulic conductivity reached the steady state flow. Specifically, the permeation was terminated when at least the four values of hydraulic conductivity were close to each other as suggested in ASTM D5084. In addition, the outflow to inflow ratio was plotted and also used to ensure the termination of the tests met the required conditions (outflow to inflow rate ranged in between 0.75 to 1.25 has to be achieved as proposed in ASTM D5084). The results of laboratory hydraulic conductivity are summarized in Figure 3.

\section{Discussion on Results Obtained Using In-situ Instrumentation}

Three type of in-situ instrumentation were employed in this study including TDR and WMPS probes. Eight TDR probes were used to capture the volumetric water content. However, Owing to the malfunction of the data acquisition and shortcoming of the sensors, only data collected from four TDR probes were analyzed. Data acquired from TDR probes were plotted and summarized in Figure 5. A volumetric moisture content range from 21 to 29 percent 
calculated using CS-tangent method presented by Topp et al. 1980. During the SDRI testing, the volumetric moisture content is constant for 3 hours and then increased by approximately 0.60 percent in Layer 1. Once the wetting front reached the TDR probes, the volumetric moisture content remain nearly constant at 240 hours (the volumetric moisture content remains constant in the range of 27 to 28 percent).

A plot of collected TDR data in Layer 2 was also presented in Figure 5. The obtained volumetric moisture content ranged from 22 to 28 percent. As shown in Figure 10, the volumetric moisture content is increasing in 119.5 hours and remains constant when the wetting front reached (at 748 hours). The data collected from the probes located in layer 3 were also plotted and presented in Figure 24. The low volumetric water contents that ranged from 24 to 25 percent were determined and increased at 1104 hours.

The data collected from the probes installed in layer 4 were also presented in Figure 5, and the volumetric water content in layer 4 ranged from 26 to 27 percent. As shown in Figure 24, significant changes occurred when the soil was subject to the drying cycle especially in layer 1 because within Layer 1 the influence of evaporation was greater than within other layers. As shown in Figure 24, the volumetric water content remained in the same range during both SDRI and drying analysis which indicated that the study analysis was completed before the wetting and drying reached the probes in Layer 4.

The heat dissipation water matric potential sensors (WMPS) were used to measure the soil matric potential of the soil. Like TDR probes, eight WMPSs were installed; however, only four sensors were analyzed in this study. The data collected from WMPS were summarized in Figure 25 . The matric potential values ranged between -10 to $1300 \mathrm{kPa},-10$ to $390 \mathrm{kPa},-10$ to 
$250 \mathrm{kPa}$ and -10 to $60 \mathrm{kPa}$ for layer 1,2,3 and 4, respectively. Unlike the volumetric water content that was decreasing during the drying cycle, the matric potential was increasing due the loss of the water. As shown in Figure 6, the soil matric suctions values were decreasing from layer 1 to layer 4. Significant changes in matric potential were observed in layer 1. This was consistent with the results obtained from TDR probes. Additionally to WMPS, the tensiometers were also to measure the soil matric suction. However, the tensiometers were decoupled from the soil during the adsorption cycle and the matric suctions obtained using WMPS were used. The tensiometers data are summarized in Figure 7.

\section{Discussion on Measured Field SWCC and k-functions}

Based on the field volumetric water content and matric soil matric potential values obtained from TDR and WMPS, the SWCCs for desorption at different location within each layer were determined (Figure 17). As described in the Chapter 4, the SWCC of depths of 6.25, 18.37, and $25.76 \mathrm{~cm}$ for Lift 1, Lift 2 and Lift 3, respectively are summarized in Figure 27. Due to the expedited timeline of the project discussed herein, the study was terminated before any significant changes in volumetric water content and matric potential occurred in the sensors located in Layer 4.

Few points were selected from each SWCC and used in RETC program to fit the obtained data to existing parametric models (van Genuchten 1980). Using the selected data points of volumetric water contents and soil matric suctions and hydraulic conductivity obtained using SDRI, van genuchten's fitting parameters were determined using RETC program. The van Genuchten's fitting parameters were used in UNSAT-H to simulate the flow in unsaturated soils. In addition, the RETC program was used to predict the hydraulic conductivity functions (k- 
function) of the soil. Based on the experimental data obtained from the sensors and hydraulic conductivity values obtained from FWP and SDRI testing, the calculated curves for hydraulic conductivity as function of the volumetric water content and soil matric potential were obtained. The details discussions on RETC and UNSAT-H were documented in the Chapter 4.

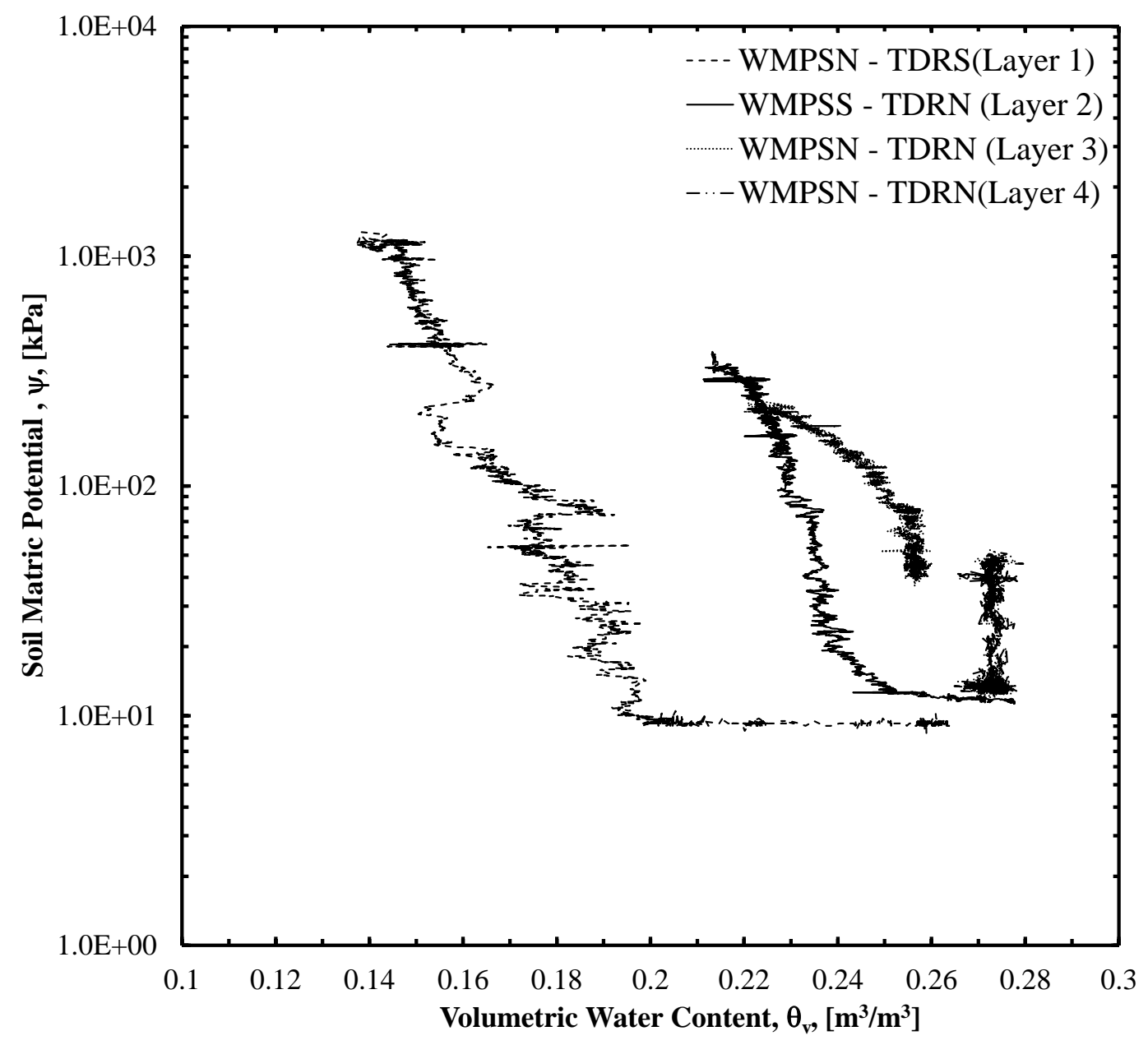

Figure 17. Field obtained SWCCS using TDR and WMPS data. 
Table 5. Data Recorded during SDRI test.

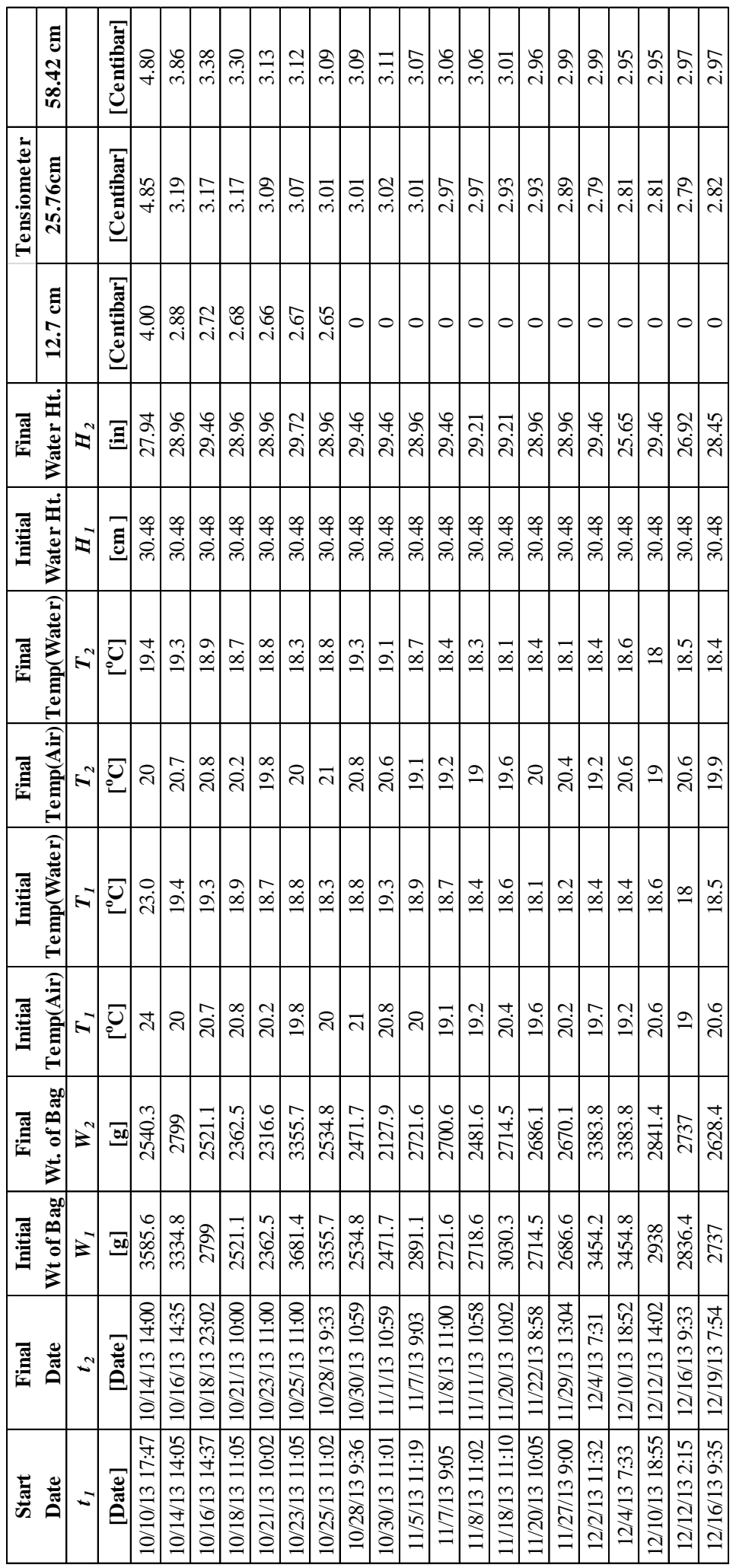


Table 6. Summary ofresults obtained from SDRI test.

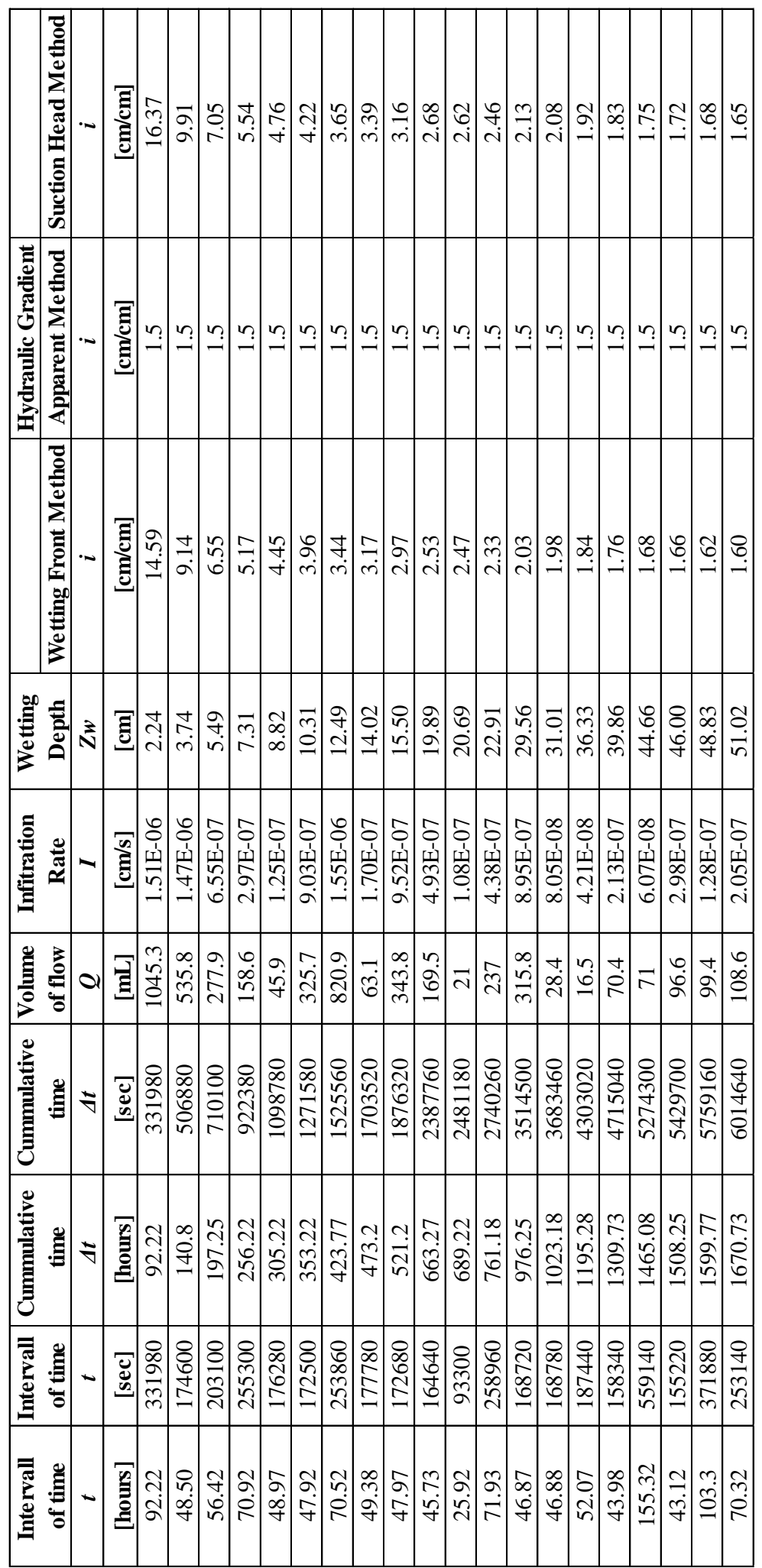


Table 7. Summary of in-situ hydraulic conductivity obtained from SDRI test.

\begin{tabular}{|c|c|c|c|c|c|c|c|c|c|c|c|c|c|c|c|c|c|}
\hline 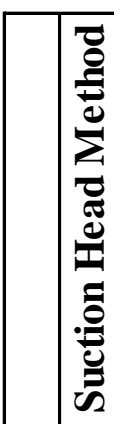 & 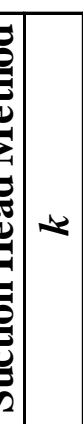 & 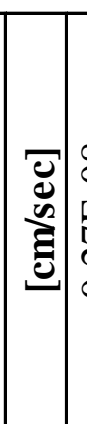 & 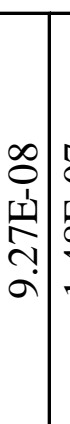 & & 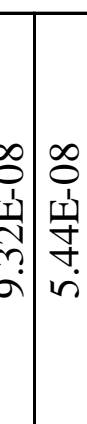 & 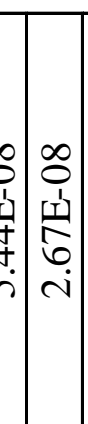 & 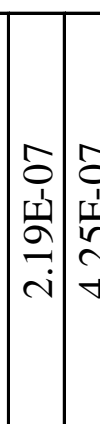 & 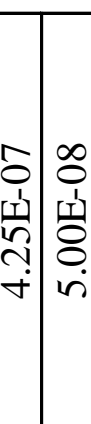 & 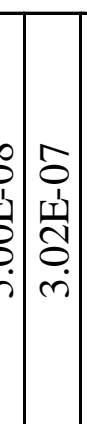 & 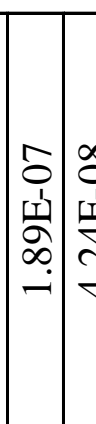 & 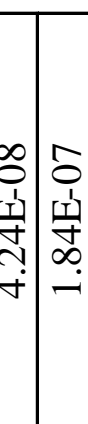 & 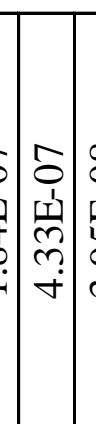 & & 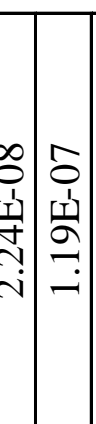 & 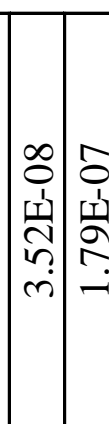 & 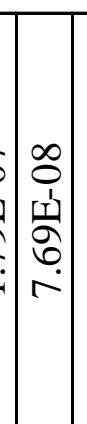 & \\
\hline 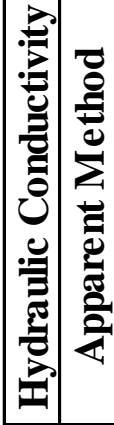 & 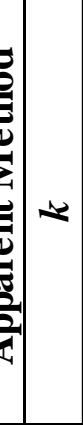 & 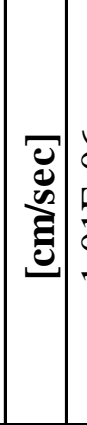 & $\begin{array}{c}8 \\
0 \\
1 \\
1 \\
0 \\
0 \\
-\end{array}$ & & 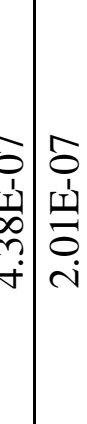 & 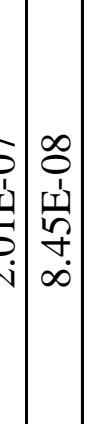 & 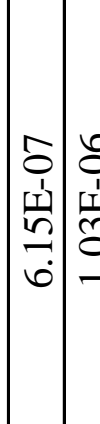 & 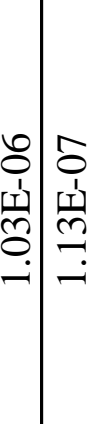 & 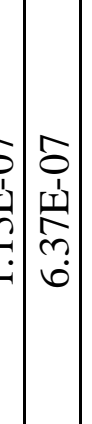 & 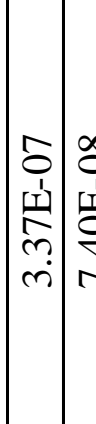 & 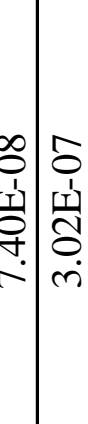 & 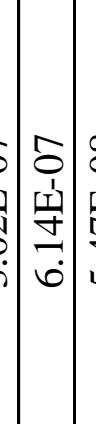 & & 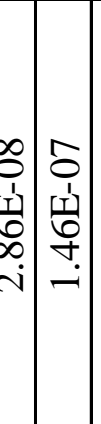 & 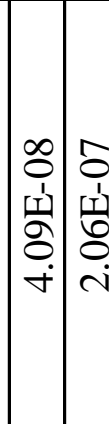 & 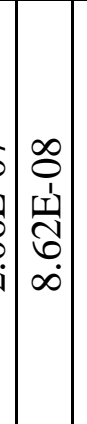 & 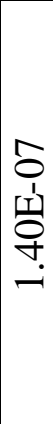 \\
\hline 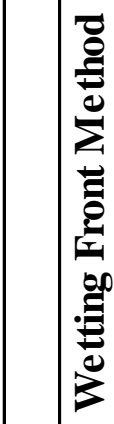 & 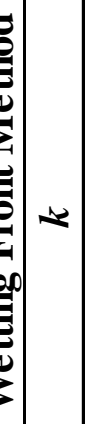 & 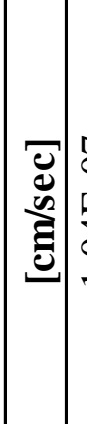 & 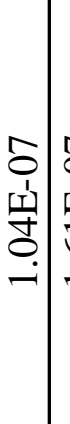 & & 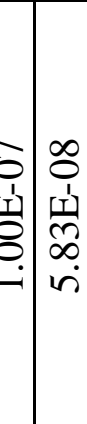 & 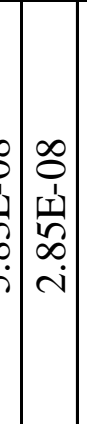 & 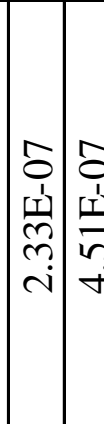 & 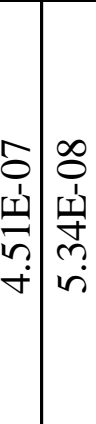 & 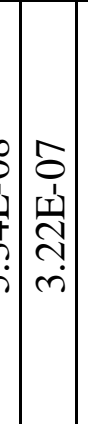 & 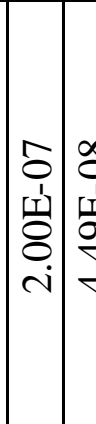 & 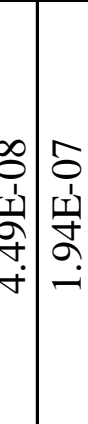 & 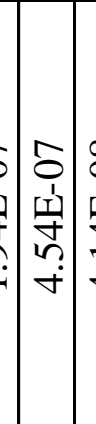 & 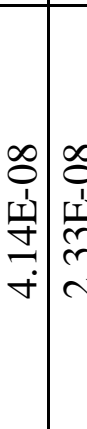 & 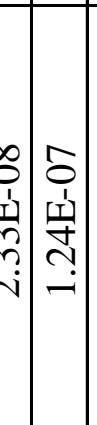 & 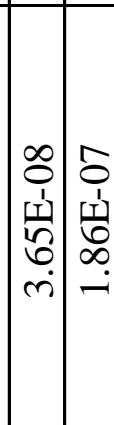 & $\begin{array}{l}\infty \\
0 \\
0 \\
1 \\
1 \\
0 \\
\vdots \\
1 \\
1\end{array}$ & \begin{tabular}{|c}
$\hat{0}$ \\
1 \\
1
\end{tabular} \\
\hline 彎 & $\begin{array}{lll} \\
\end{array}$ & 包 & 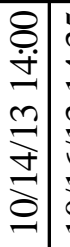 & 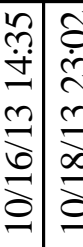 & 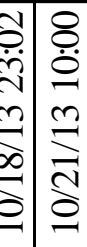 & 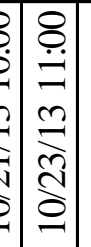 & 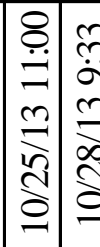 & 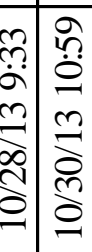 & 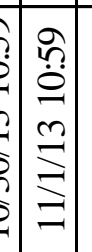 & 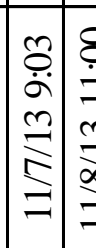 & 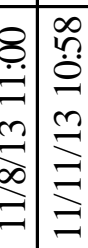 & 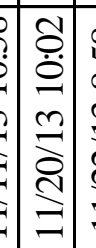 & 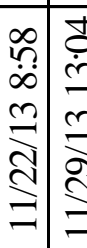 & 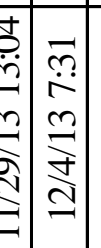 & 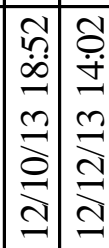 & 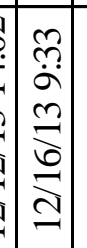 & 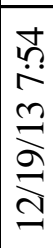 \\
\hline 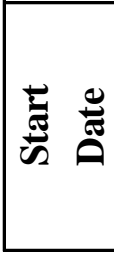 & 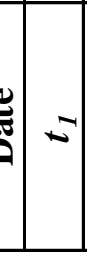 & 总 & 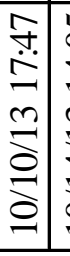 & 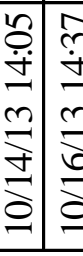 & 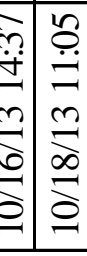 & 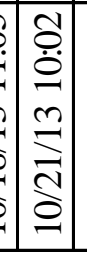 & 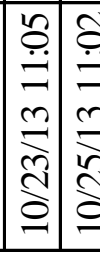 & 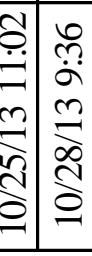 & 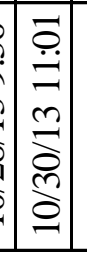 & 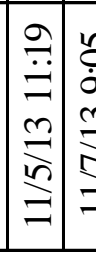 & 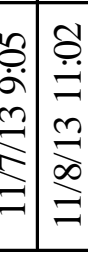 & 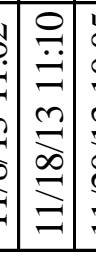 & 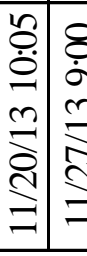 & 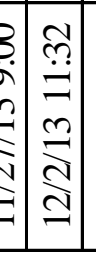 & 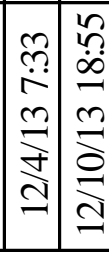 & 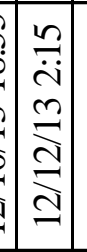 & $\stackrel{2}{2}$ \\
\hline
\end{tabular}

